University of Louisville

ThinkIR: The University of Louisville's Institutional Repository

Electronic Theses and Dissertations

$5-2017$

\title{
Tonal shift, cadence and transition in the brass sonatas of Paul Hindemith.
}

Blake Taylor

University of Louisville

Follow this and additional works at: https://ir.library.louisville.edu/etd

Part of the Music Theory Commons

\section{Recommended Citation}

Taylor, Blake, "Tonal shift, cadence and transition in the brass sonatas of Paul Hindemith." (2017). Electronic Theses and Dissertations. Paper 2658.

https://doi.org/10.18297/etd/2658

This Master's Thesis is brought to you for free and open access by ThinkIR: The University of Louisville's Institutional Repository. It has been accepted for inclusion in Electronic Theses and Dissertations by an authorized administrator of ThinkIR: The University of Louisville's Institutional Repository. This title appears here courtesy of the author, who has retained all other copyrights. For more information, please contact thinkir@louisville.edu. 
TONAL SHIFT, CADENCE AND TRANSITION IN THE BRASS SONATAS OF PAUL HINDEMITH

\author{
By \\ Blake Taylor \\ B.M., University of Kentucky, 2014
}

\begin{abstract}
A Thesis
Submitted to the Faculty of the

for the Degree of

Master of Music

in Music Theory

School of Music

University of Louisville

Louisville, Kentucky
\end{abstract}

School of Music of the University of Louisville

in Partial Fulfillment of the Requirements

May 2017 
Copyright 2017 by Blake Taylor

All rights reserved 

TONAL SHIFT, CADENCE AND TRANSITION IN THE BRASS SONATAS OF PAUL HINDEMITH

\author{
By \\ Blake Taylor \\ B.M., University of Kentucky, 2014
}

A Thesis Approved on

April 21, 2017

by the following Thesis Committee:

Thesis Director

Mark J. Yeary, Ph.D.

Rebecca Jemian, Ph.D.

Devin Burke, Ph.D. 


\section{DEDICATION}

This thesis is dedicated to the memory of my grandparents: Polly Gaddis, Jimmy Gaddis and Maxine Taylor, without whom I would never have achieved what I have achieved, learned what I have learned or been loved as much as I have been loved. 


\section{ACKNOWLEDGEMENTS}

This thesis would not be possible without the indelible knowledge, wit and wisdom of Dr. Mark J. Yeary, who continued to meet with me while three time zones away. His impact on this document is nearly immeasurable, and I am indebted to his analytical mind and penchant for probing questions. I cannot overstate the appreciation I have for the other music theory faculty at the University of Louisville, especially Dr. Rebecca Jemian, who was always available for commentary, advice

and guidance throughout my time at the university. I would also like to acknowledge Dr. Devin Burke and Dr. Eric Hogrefe for their helpful input, commentary and assistance with this document. Special thanks to Tim Bausch for being a constant sounding board and officemate-cum-confidant during the creation of this thesis. Finally, I would like to thank my parents, Todd and Tammy, and my fiancée Emma, who has been incredibly patient and a constant source of strength throughout this process. 


\section{ABSTRACT \\ TONAL SHIFT, CADENCE AND TRANSITION IN THE BRASS SONATAS OF PAUL HINDEMITH \\ Blake Taylor}

April 21, 2017

This thesis examines analytical facets in Paul Hindemith's sonatas for brass and piano, ranging in date of composition from 1938 to 1955, while also considering Hindemith's role as a neoclassicist and how these works help inform and shape our knowledge of Hindemith's neoclassicism. The document is divided into four chapters: Hindemith and Tonality, Analytical Concerns and Methods, Brass Sonata Analyses, and Hindemith and Neoclassicism. As a fundamentally neoclassical composer, Hindemith combined traditional aspects of form with new applications of tonality, establishing within his music various levels of what he termed "key areas." Through analyzing the corpus of sonatas for solo brass and piano, mid-level cadential and transitional phenomena become apparent. In particular, the descending half step is frequently used to navigate key areas that occupy multiple hierarchical levels of tonal space. These mid-level structures are revealed to have 
overarching hierarchical implications and ultimately inform our knowledge of Hindemith's neoclassical style. 
TABLE OF CONTENTS

DEDICATION

CHAPTER 1: HINDEMITH AND TONALITY...................................................................... 1

CHAPTER 2: ANALYTICAL CONCERNS AND METHODS......................................................22

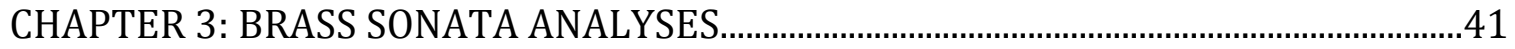

ANALYSIS I: SONATA FOR TROMBONE AND PIANO

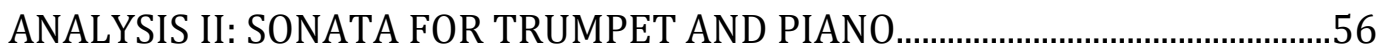

ANALYSIS III: SONATA FOR TUBA AND PIANO .....................................................63

CHAPTER 4: HINDEMITH AND NEOCLASSICISM: THE HORN SONATA AND

VARIABILITY OF TERMINAL STRUCTURE.......................................................................

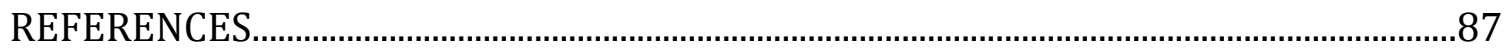

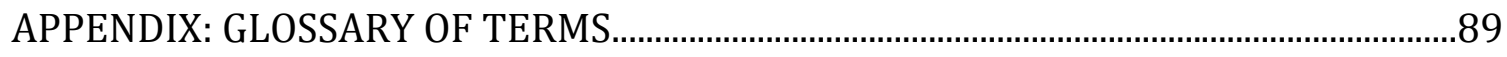

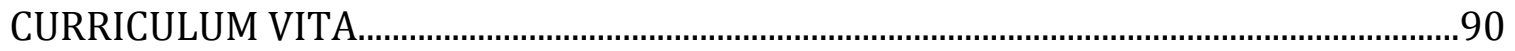




\section{LIST OF EXAMPLES}

EXAMPLE

PAGE

1.1 String Quartet no. 2, 0p. 10, mm. 1-6.

1.2 Sonata for Trombone and Piano, mm. 20-26..................................................................11

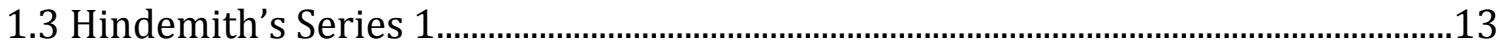

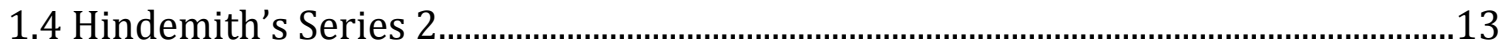

1.5 Mathis der Maler, mm. 101-107 .............................................................................

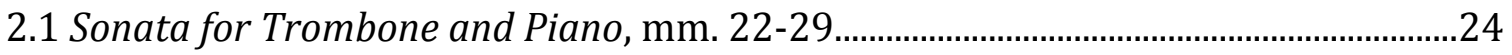

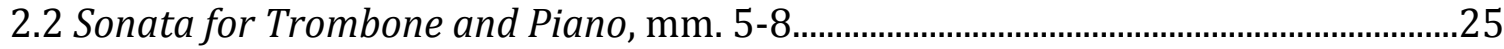

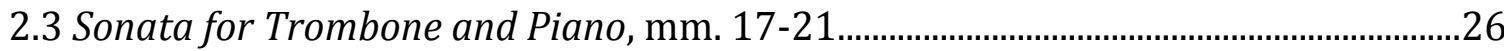

2.4 Essential Expositional Trajectory Diagram....................................................................28

2.5 Sonata for Trombone and Piano, mm. 20-27, annotated..............................................38

3.1 Sonata for Trombone and Piano, mm. 1-4 ..................................................................... 44

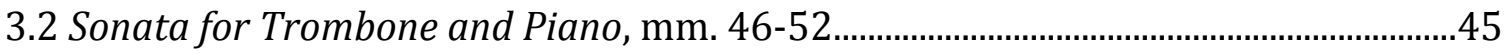

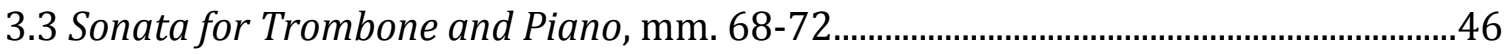

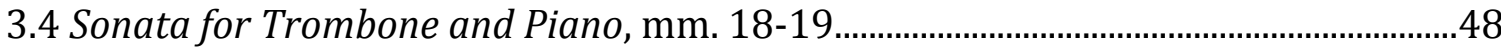

3.4.1 Sonata for Trombone and Piano, mm. 37-42 .........................................................

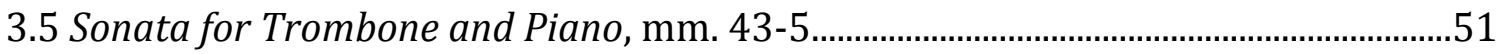

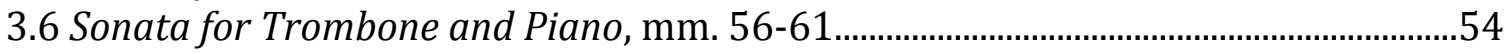

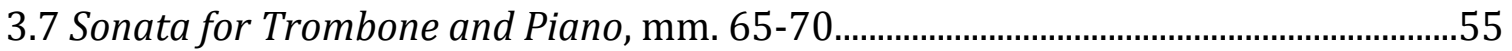

3.8 Sonata for Trumpet and Piano, trumpet part, mm. 1-4...............................................58

3.9 Sonata for Trumpet and Piano, piano part, mm. 1-4....................................................58

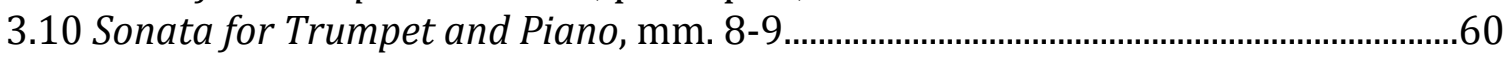

3.11 Sonata for Trumpet and Piano, mm. 15-16..................................................................61

3.12 Sonata for Trumpet and Piano, mm. 23-25..............................................................61

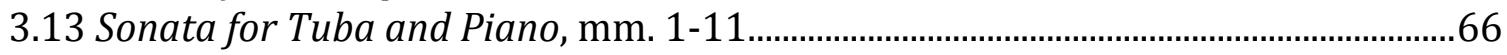

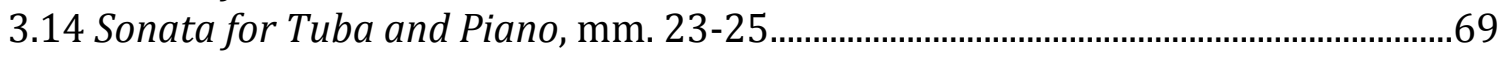

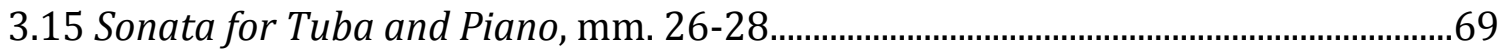

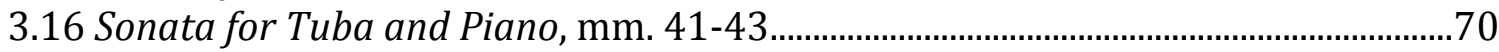

4.1 Sonata for Horn and Piano, mm. 61-66.......................................................................... 74

4.2 Sonata for Horn and Piano, mm. 103-106......................................................................75 


\section{LIST OF FIGURES}

FIGURE

PAGE

3.1 Hindemith's sketch of Sonata for Trombone and Piano, mvt. 1..................................44

3.2 Sonata for Trombone and Piano key areas and formal labels........................................47

3.3 Sonata for Trumpet and Piano key area interpretation and formal labels.............57

3.4 Sonata for Tuba and Piano key area interpretation and formal labels....................64 


\section{CHAPTER 1}

\section{HINDEMITH AND TONALITY}

"We are no longer prisoners of the key."

—Paul Hindemith ${ }^{1}$

Tonality is generally regarded as a cornerstone of most Western music traditions before the twentieth century, and what might be considered the mortar that holds that cornerstone in place is the notion of keys. What would Beethoven's first piano sonata be if not in F minor? And what would Mahler's first symphony be, despite the local variance and tonicizations, if not in D major? How could these classical formal structures, carrying so much baggage even in their names of "sonata" or "symphony," ever divorce themselves from something so basic as the key without uprooting that fundamental cornerstone of tonality?

Enter Paul Hindemith, something of a musical oddity: a composer that is often-performed, but seldom analyzed critically; a composer whose fifty-year pedagogical and compositional career is expansive, but who can be found to only be

${ }^{1}$ Geoffrey Skelton, Paul Hindemith: The Man behind the Music: A Biography (London: Victor Galancz, 1977), 152. 
given lip service in music history courses and texts. Perhaps that lip service comes as being included as a footnote in a broader discussion of twentieth-century neoclassicism, which generally begins and ends with Stravinsky, or perhaps it comes from hearing about the opposition to serialism and expressionism in the early part of the century. Nevertheless, Hindemith specifically and neoclassicism in general tend to be two topics, perhaps not overlooked but at least underlooked, as a basis for serious analytical inquiry. In his quote above, Hindemith not only brings tonality into question, but also portrays keys-a fundamental aspect of most conceptions of tonality—as a prison to which musicians are beholden.

Although Hindemith wrote extensively on his theories of tonality and composition, a heretofore-unexamined aspect of his music is that of mid-level formal structures, such as the cadence and transition, which are only given a perfunctory explanation in his notes. Summarily, Hindemith scholars such as David Neumeyer have likewise not analyzed at length these mid-level compositional phenomena.

Does Hindemith's status as a neoclassicist not necessitate an examination of such mid-level structures? While authors such as David Neumeyer have investigated both large-scale and small-scale aspects of classical and neoclassical paradigms, both top-down and bottom-up analyses meet at the middle ground, which has yet to be given a satisfactory treatment. While I make no bold claim to enlighten the reader on some of these very important overarching matters, I have distilled some of these concepts and concerns into a blended approach that addresses the dichotomy of Hindemith's neoclassicism and radical repurposing of tonality, as well 
as bring to light the ways Hindemith's music functions on a more local level. The purpose of this document is to illuminate mid-level formal structures while remaining in dialogue with Hindemith's status as a neoclassicist through the intrinsic neoclassical formal constructs within his sonatas.

To begin to untangle some of these threads, I will give a brief biographical overview of Hindemith and associated scholarship to discuss his conceptualizations of tonality, cadence and transition through the lens of his Craft of Musical Composition. After establishing these building blocks, in later chapters I will provide an analytical method of classifying and identifying ways in which Hindemith uses mid-level phrasal functions through the lens of the specific corpus of brass sonatas. I will follow with an in-depth analysis of these works using the prescribed techniques, and end the document with conclusions on functional typology as well as reflections of Hindemith as a neoclassicist, including how listening and conceptualizing these medium-scale formal cues gives credence to Hindemith's pedagogical ethos and reinforces the importance, acceptance and understanding of neoclassicism in the mid-twentieth century. Throughout the course of this document, it is my hope that the reader becomes more aware of the particulars of Hindemith's theories of tonality, reconsiders his neoclassicism, and becomes more aware of delineating structures in music that is ostensibly neoclassical.

Paul Hindemith (1895-1963) is renowned as a composer, performer, pedagogue and music theorist of the early- to mid-twentieth century. His career took an early start, and by age 32 he had been appointed professor of composition at the Berlin Musikhochschule, one of the top academic institutions in Germany. 
Hindemith also found success as a performer of viola, leading to the promotion and advocacy of contemporary music in his travels with his Amare Quartet. ${ }^{2}$

Although in his early career as a composer he considered himself an embodiment of the neue Sachlichkeit, or New Objectivity movement, Hindemith's style eventually evolved into a blending of a distinct twentieth-century tonal style constrained by formal concepts that recall Viennese classicism. Indeed, as Heinrich Strobel portrays in his 1948 biography of the composer, Hindemith apologists extolled Hindemith's virtue as the neue Typus, "the antiromantic urban composer who thrived on clarity, concision, and linear energy rather than on the late romantics' diffuse forms, exaggerated emotion, and tortured harmonic logic."3

In general, the discourse of Hindemith's theories is not a widely-probed point of academic research in the modern scope of music theory, perhaps suggesting that the theories are currently either invalid, outdated or otherwise supplanted. Most twentieth century primers and music history texts do give some mention of Hindemith, typically regarding neoclassicism; his tonal constructs are rarely approached or considered in the same way as is, say, the Second Viennese School. Perhaps this reflects Hindemith's fundamental conservatism; as he was viewed and disseminated as a neoclassicist, it is possible the conservative baggage that term carries taints his overall reception. Even regarding neoclassicism, most texts prefer the music of Igor Stravinsky as a conduit of discourse. Does this imply that

${ }^{2}$ David Neumeyer, The Music of Paul Hindemith (New Haven: Yale University Press, 1986), 1.

3 Ibid, 2. 
Hindemith's tonality—not only his theories of tonality, but also the music itself-has lost poignancy or effect over the years?

Numerous authors have portrayed Hindemith as a composer that was overlooked or dismissed during his career. Ian Kemp, in his 1970 monograph, provides the observation that "like [J.S.] Bach, [Hindemith] was considered an antiquated irrelevance during his lifetime."4 In this same vein, David Neumeyer notes that "[e]ven at the height of Hindemith's reputation and influence ... stylistic changes in serious and commercial music were beginning that quickly left Hindemith behind." ${ }^{5}$ Neumeyer supports this point by alluding to the adoption of electronic sound palettes, jazz idioms and hyperserial technique by contemporary composers of the mid-twentieth century, all of which Hindemith was reluctant to utilize in his own work. To expound upon Kemp's Bach parallel, Neumeyer writes that

Hindemith had the same unsettling tendency to infect his music with the qualities of the 'learned mathematician,' as Scheibe labeled Bach: abstract symbolism, an apparent lack of interest in instrumental color, and an off-putting tone of didacticism. Like Bach in the 1780s, Hindemith's reputation is covered with clichés fair and false which have clung to him more tenaciously than any of his contemporaries. ${ }^{6}$

Other critics have levied complaints against Hindemith; Theodor Adorno similarly assails Hindemith for being "bourgeois and unimaginative, not profound" and "a dogmatic theorist"7 and Arnold Whittall, writing on Hindemith's later career, notes that "it is infinitely sad that Hindemith's later music gives no more than an

\footnotetext{
${ }^{4}$ Ian Kemp, Hindemith (Oxford University Press, 1970), 56.

${ }^{5}$ Neumeyer, 7.

6 Ibid.

${ }^{7}$ Ibid, 11.
} 
occasional flicker of a positive conservatism which could have balanced [his] youthful excesses of the 1920s." ${ }^{8}$

These rebukes by Hindemith's contemporaries paint a different picture of the composer we might imagine today: an old conservative, sticking stodgily to his books that were ineffectual outside of his circle at Yale, writing in the traditional formal paradigms of sonata, string quartet, and other formalized chamber music. This sort of refutation perhaps colored the lack of adoption of Hindemith's theories and works into the history books; Hindemith gained significant criticism and even dismissal during his lifetime, and so his contemporaries writing the books for the next generation were summarily dismissive. This dismissal by philosophers such as Adorno also perhaps contributed to the perceived preference of Stravinsky over Hindemith when referring to neoclassical ideals and methods in the general musicological discourse. ${ }^{9}$

Although some of Hindemith's students at Yale, such as Bernhard Heiden, went on to be successful composers, none were as successful or as popular as their teacher. This lack of a clear composition family tree has led to Hindemith's methods and tonality typology to be somewhat dismissed, misunderstood, or debated by modern scholars. Late-twentieth-century scholarship produced after Hindemith's

8 Ibid, 12.

${ }^{9}$ A further inquiry might consider the reception of Stravinsky within the same period. In general, Hindemith's method of tonality appears to be something of an orphan of influence in the realm of composition, rather analogous to the autonomous style of Bela Bartok. In other words, although Hindemith's theories and scholarship have borne great weight in music theory circles, particularly after the mid-twentieth century, it is difficult to discern to whom or from whom Hindemith owes or is owed influence; his musical sphere of influence was limited compared to the likes of Stravinsky or Schoenberg. 
death seems to begrudgingly cede some relevance to Hindemith's musical method, usually in regards to his disdain for overt diatonicism or under a broader discussion of some of the particular theoretical and musicological constructs found within the Craft. It should be noted that only well after the publishing of Craft was Hindemith regarded as having "matured" as a composer. ${ }^{10}$

However, Hindemith's contributions to the broader field of music theory are not unnoticed; musicologist Alan Bush calls Craft one of the six most important books of twentieth-century music literature. ${ }^{11}$ Igor Stravinsky referred to the three most important neoclassical lineages of the early twentieth century: his own, Arnold Schoenberg's, and Hindemith's. ${ }^{12}$ While Hindemith's theories might acquire a degree of prominence or noteworthiness among certain scholars, Hindemith's tonality and musical methods are sometimes given a brush-over by other authors. This is exemplified by Jim Samson, who writes that "[f]or some theorists, 'tonality' has been understood in such broad terms that the concept of 'atonality' becomes entirely meaningless." ${ }^{13}$

While it is important to note that, as Samson points out, the definition of tonality becomes somewhat amorphous after the turn of the century and the promulgation of various systems of atonality, Samson's dismissal and subsequent reduction of Hindemith's broad tonal palette warrants a re-examination of Hindemith's idiom. By understanding Hindemith's particular tonal schemes and

\footnotetext{
${ }^{10}$ Neumeyer, Music of Paul Hindemith, 242-244.

11 Payne, 201.

12 R. James Tobin, Neoclassical Music in America: Voices of Clarity and Restraint (Lanham, Maryland: Rowman \& Littlefield, 2014), 1.

13 Samson, 152.
} 
how they are more influenced by melody, motive and linearity than the absolutes of harmonic framework, a deeper understanding of the music is achieved. Although Samson's passage above-one of the scant mentions amid his multiple chapters on twentieth century tonality—perhaps misses the more specific picture of Hindemith, he does give a succinct overview of the hallmarks of twentieth century tonality, saying that

[i]t will already be clear that the term 'tonality' is commonly used in two senses, referring on the one hand to the specific language of 'classical tonality' ... and on the other to the underlying principle ... that has been broadly defined ... as 'the requirement that all the events in a musical group should be co-ordinated by, and experienced in relation to, a central point of reference. ${ }^{14}$

While these issues are wide and varied, this discussion only begins to get at the heart of the crux of Hindemith's tonality and its neoclassical, structural implications. It is my hope that in the following chapter, cogent analyses will be provided that flesh out these concepts even further by providing an analytical background on how that tonality functions in medium-scale formal constructions. In particular, I will begin to investigate medium-scale constructs of cadence and transition, and give analytical treatment to the specific corpus of the brass sonatas.

While Hindemith's neoclassicism is an important-if not the most important—feature of his work, the most striking and autonomous aspect of Hindemith's music is the unique tonal system he adopted and portrayed through his seminal 1939 book The Craft of Musical Composition. Although Craft is a dense volume with both pedagogic and theoretical ramifications, it ultimately shows the development and reasoning behind Hindemith's theories of tonal architecture. To

${ }^{14}$ Ibid, 151. 
better understand the lower-level intricacies of Hindemith's works, his hierarchical tonal system must be discussed and understood, at least at a perfunctory level.

The threads between Hindemith and tonality are inextricably linked, as Hindemith is well known for his theories and methods of tonal craftsmanship. As previously stated, Hindemith's style underwent a gradual change; although his earliest works exhibited an evolution from the late Romantic era to the sort of expressionism and free atonality espoused by Schoenberg, they were all rife with counterpoint and strong linear motion that exemplified the neue Sachlichkeit ideal. To further illustrate this evolution of tonality as a test case, I present selections from an early string quartet and the later trombone sonata, which I will be examining in a later chapter. 


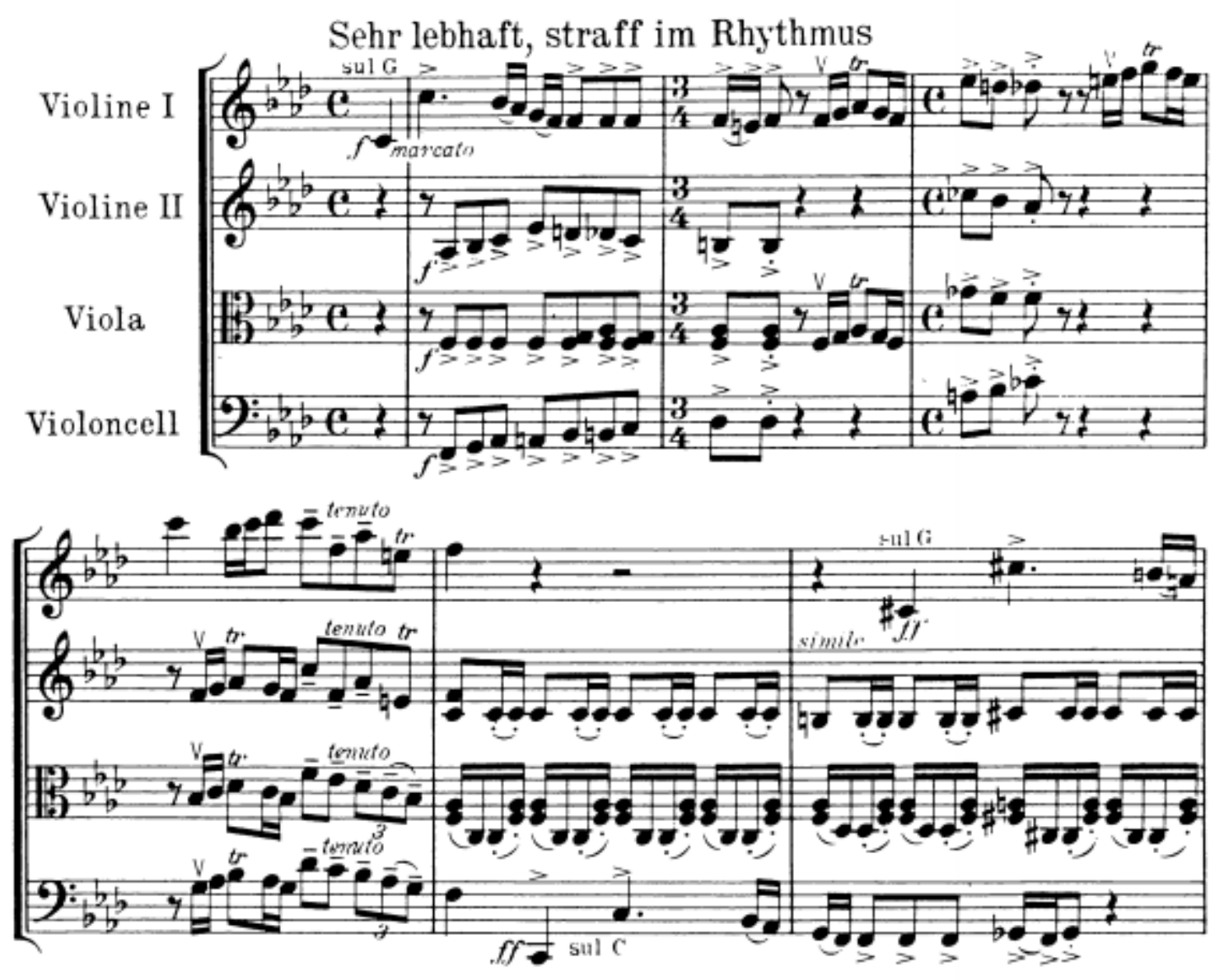

Example 1.1 String Quartet no. 2, op. 10, mvt. 1, mm. 1-6

The first movement of Hindemith's String Quartet, no. 2 (1918) displays a sense of chromatic motion and a degree of autonomy between the voices, yet illustrates that aside from a few instances of chromaticism, at this point Hindemith is operating at a globally tonal level, perhaps just slipping away from the umbrella of the long nineteenth century and beginning to experiment with chromatic elements while remaining firmly diatonic. Therefore, the second string quartet is entrenched firmly in the late Romantic ideal. It is not until later in Hindemith's career that a 
unique style begins to emerge, exhibiting what David Neumeyer calls "clarity, concision, and linear energy."15

An example of Hindemith's evolving tonal style from a later period is shown below in the first movement of Hindemith's Sonata for Trombone and Piano, from 1941. This is a piece that I will be visiting often, as its tonal palette allows many of the relationships and analytical methods discussed in this document to come to light.
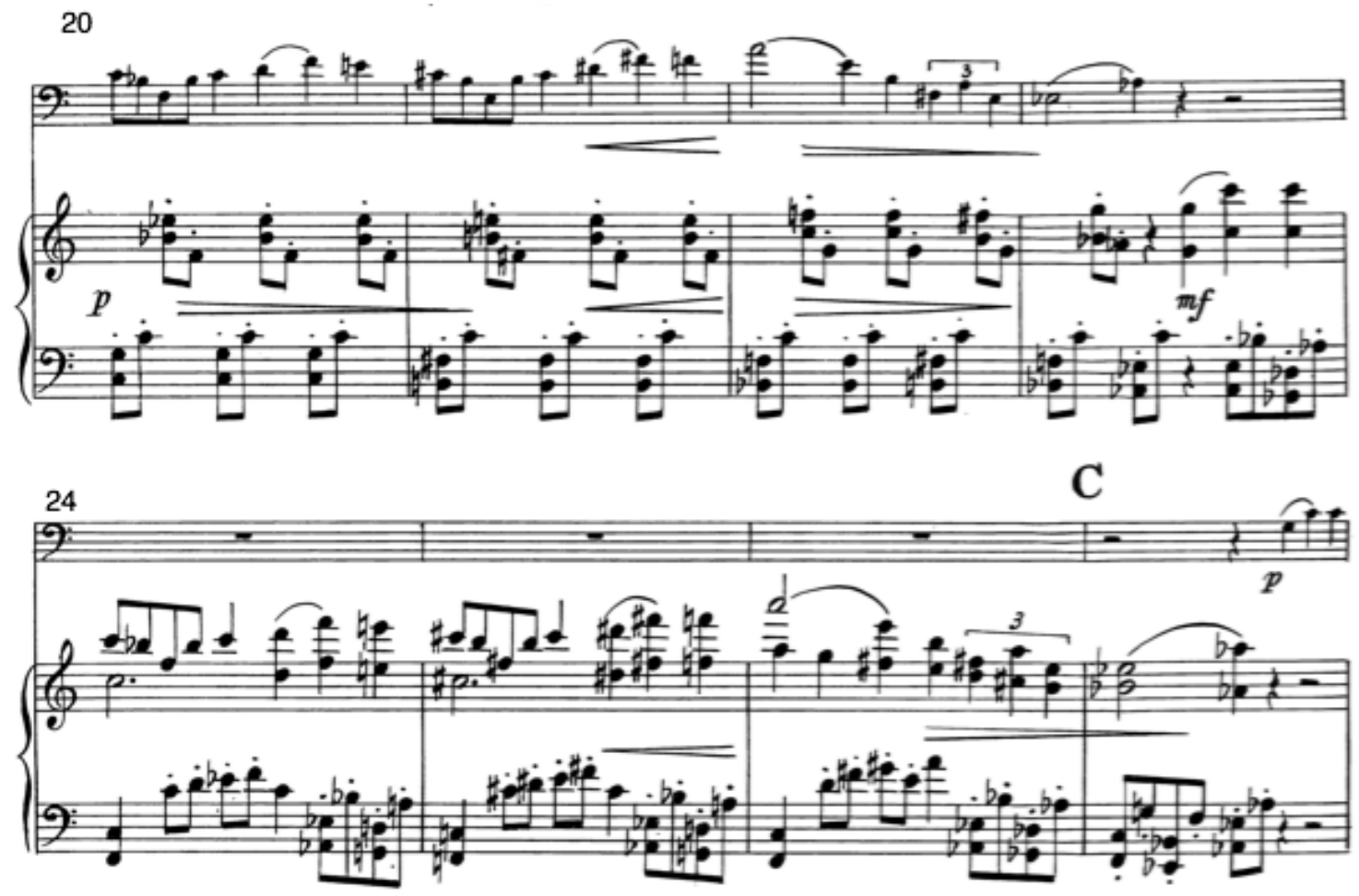

Example 1.2. Sonata for Trombone and Piano, mm. 20-26

The trombone sonata is an example of Hindemith's contrapuntal tonality that is largely disseminated in The Craft of Musical Composition. Hindemith, as evidenced 15 Tobin, 22. 
by his sketches and notes, considered this section in Example 1.2 in the key area of C. There are certain structural constructs here that reinforce that notion: the presence of a grounded bass $\mathrm{C} / \mathrm{G}$ dyad in bar 20 and the reinforcement of $\mathrm{C}$ in the trombone theme that is later picked up in the piano at bar 23, for instance. Yet, a striking feature of this area is the lack of what we might typically consider a given for an established tonal section in a key. The absence of triads is aurally striking and is a hallmark of Hindemith's style; triads are only occasionally employed as a way to give an emphatic structural ending to a section.

The aspect of non-triadic tonality is reconciled within Craft. As the works I will be examining in this document date from approximately that era of Hindemith's life, Craft provides a good starting point for distilling some of Hindemith's theories and expounding upon how Hindemith treats tonality.

Within Craft, Hindemith developed a very specific view on the purpose of tonality and its structural application in his music. He devised two systems of categorization for pitches: Series 1, which dealt with pitches in relationship to one another, as in a melody; and Series 2, which concerned the combination of tones and their ranking from least dissonant to most dissonant. Both the Series can be adapted to relate to any note or tonal center. Below, Example 1a and 1b show this linear relationship between tones as related to C. According to Hindemith's view, tones and intervals on the left are more consonant, growing gradually more dissonant as 
they progress to the right.

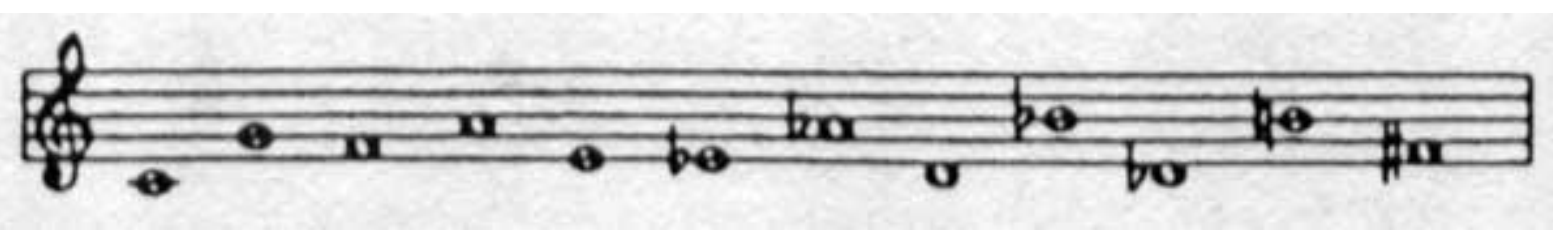

Example 1.3 Hindemith's Series $1^{16}$

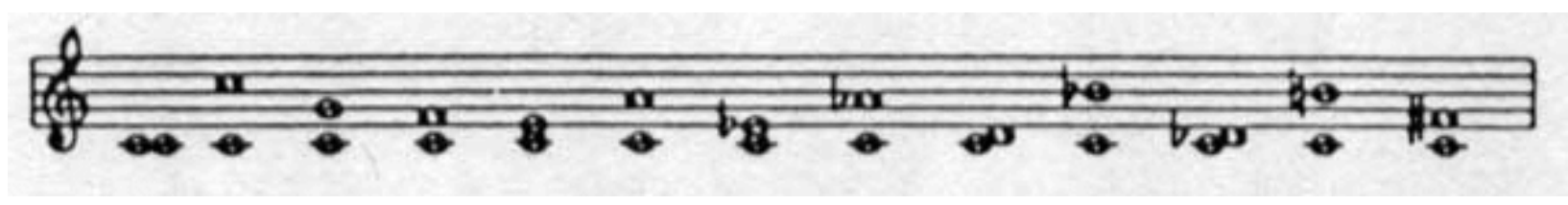

Example 1.4 Hindemith's Series $2^{17}$

Hindemith writes at length in Craft on the relationship between the two

systems. He summarizes them as such:

Series 1 consists of tones, in relation to a progenitor tone from which they derive their tonal position. Series 2 consists of intervals, without relation to a progenitor tone ... the interval-pairs do not indicate by a gap of any kind that there is any point at which the consonances stop and the dissonances begin. The two concepts have never been completely explained, and for a thousand years the definitions have varied. ${ }^{18}$

Hindemith's quasi-scientific approach of classifying and approaching intervals with respect to the harmonic series (relating to the "progenitor tones" he recalls in the passage above) was systematic, yet allowing for a wide range of tonal possibilities, and he eventually attained a sort of global adoption of this method in

\footnotetext{
16 "Principles and Categories," Fondation Hindemith, accessed April 3, 2017, http://www.hindemith.info/en/life-work/biography/1933-1939/work/principlesand-categories/.

17 Ibid.

${ }^{18}$ Hindemith, 84.
} 
his own compositions and within his pedagogical method. Indeed, the entire second volume of Craft is a pedagogical exercise book, allowing for students to complete musical examples in the light of Hindemith's system of tonal relationships. It should also be noted that, despite the prevalence of these pitch and harmony relationships, the detail of which is too intricate for the context of this document, Hindemith frequently broke his own "rules," as they were, for compositional effect, much as composers of the nineteenth century broke the established "rules" of counterpoint or harmony to further broaden their compositional palette.

Craft was written approximately concurrently with Hindemith's famed opera Mathis der Maler, which was completed in 1935 and premiered in 1938, and is considered the first full companion piece for Craft, showing the presence and utilization of some of these theories. Mathis then represents the early culmination of development and formalization of the theories within Craft, allowing Hindemith a musical space to nuance and perfect his conceptions of neotonality. See in Example 1.5 below an example from the first movement of the version of Mathis for orchestra, exemplifying the same atriadism and quartality that Hindemith so often employs in his later period and that is evidenced in the brass sonatas that will bear later analyses. 


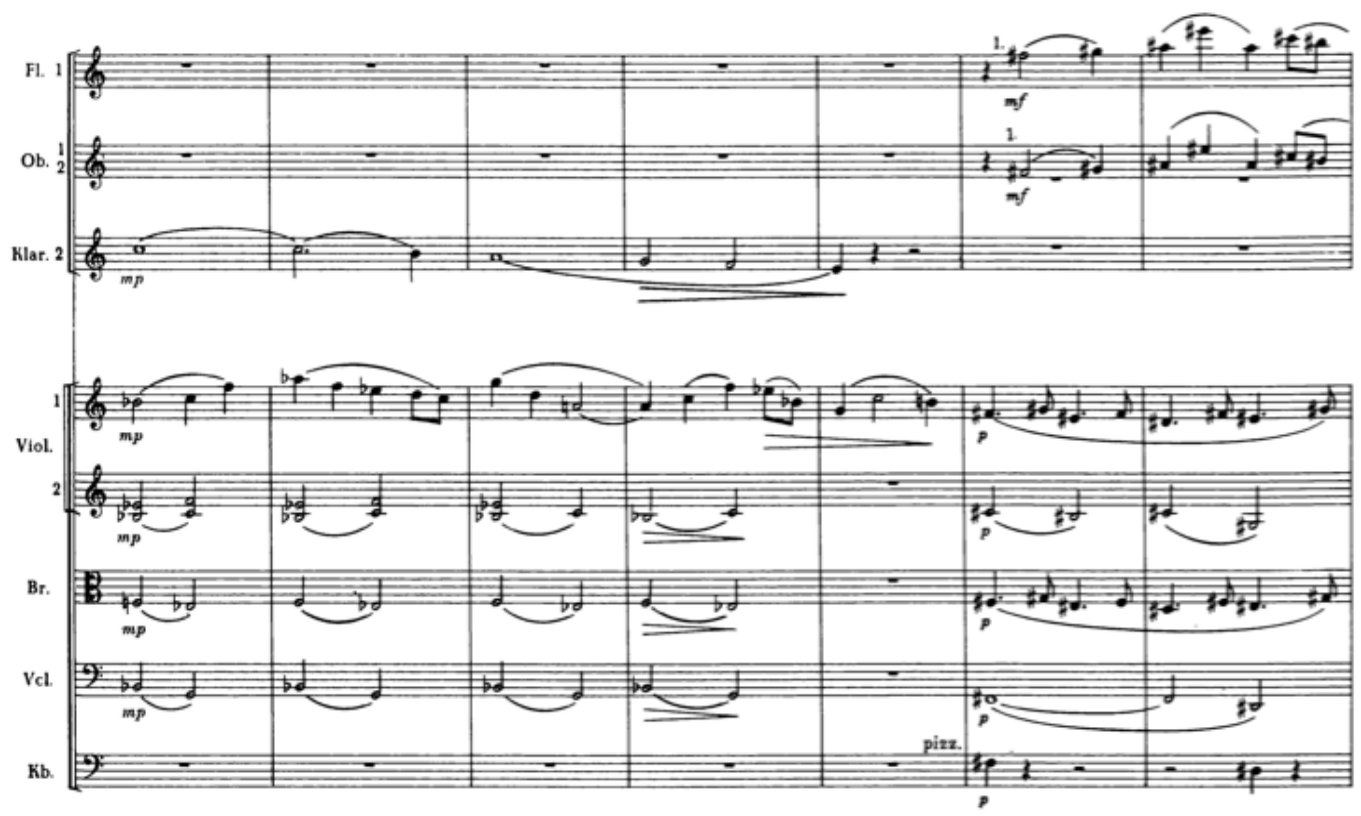

Example 1.5 Mathis der Maler mm. 101-107

Within this excerpt from Mathis, one observes a divergence from the clear tonal stylings of Hindemith's earliest work, yet there pervades a sense of overarching tonal gravity of sorts; here, the repetition of the quartal-flavored $\mathrm{Bb}$ chords is the recipient of this gravity. ${ }^{19}$

To better understand Hindemith's tonal system, I will turn to multiple authors who have given their impressions of Hindemith's tonality and discussed it at length. Jim Samson portrays Hindemith's system as "a sort of competition for

${ }^{19}$ An even more dynamic example of Hindemith's turn from the prior neue Sachtlichkeit style to the later introduction of neotonal concepts is manifested into practice with his extensive rewrite and revision of the song cycle Das Marienleben, which was completed by 1948, contemporary with the brass sonatas that will be analyzed in a later chapter. 
dominance of the individual tones in a melodic line or harmonic succession."20

Samson goes on to point out that

[t]he clearest expression ... is to be found in the new tonal languages ... of the twentieth century, in which the tonal principle has been reinterpreted in a way which excludes, or greatly minimizes the importance of, diatonic relationships. ${ }^{21}$

Other scholars have summarized Hindemith's tonality in a way that expressly probes the most present and surface-level facet of his music, as has Samson above: the prominence of non-diatonic tonicism as a compositional content tool. Dorothy Payne, in her 1974 dissertation on Hindemith's wind sonatas, gives credence to some of Samson's ideas:

It should be noted here that the terms "tonal" and "tonality" refer in a largely subjective sense to the presence of a pitch, or group of pitches, which exert some sort of gravitational pull on the surrounding material ... the tuba sonata being the most significantly different in its extreme and consistent chromaticism. ${ }^{22}$

On the phenomena of the sort of lack of diatonicism within Hindemith's sonatas, Payne observes:

It is rare that one finds a structural unit of significant size in which adherence to a diatonic scale is absolute; in fact, there are relatively few examples of even single phrases which fit this narrow description. When such a passage does occur, the scale tends to be modal, and the effect is usually harmonically static, more suggestive of pandiatonic technique than of functional harmonic progression. ${ }^{23}$

Although this is a rather distilled take, Payne's initial description reflects and informs that of Samson's above. Language such as "competition," "dominance,"

${ }^{20}$ Jim Samson, Music in Transition (Oxford University Press, 1995), 152.

${ }^{21}$ Ibid.

22 Dorothy Payne, "The Accompanied Wind Sonatas of Hindemith: Studies in Tonal Counterpoint," (dissertation, Eastman School of Music, 1974), 202.

23 Ibid. 
"gravitational pull," and "subjective" do not necessarily relate directly to Hindemith's music; although they are in some ways derived from Hindemith's own works, they do not give the reader reassurance that these systems of tonality are definite in the same way that eighteenth and nineteenth-century tonality might be. Although the best method for quantifying and understanding Hindemith's tonality would be through a thorough reading of Craft, other authors have commented on this underlying phenomena and aura of reluctance with regards to acknowledging Hindemith's works.

Renowned Hindemith scholar David Neumeyer provides perhaps the clearest and most thorough examination of Hindemith's various theories and tonal characteristics within his music in his seminal 1986 book The Music of Paul Hindemith. Neumeyer writes that Hindemith regarded the phenomena of harmony as hierarchically subordinate to tonality. ${ }^{24}$ Neumeyer further states "contextual factors also play a surprising role in the definition of tonality ... his attitudes reflect his intense pragmatism."25 Unlike Schenker, Hindemith disregarded his tonal system as "preexistent in the nature-given material of the major triad" and that "the tonal principle is unavoidable; but to pattern music most successfully, one has to do some work." ${ }^{26}$ These passages perhaps reflect a shift in attitudes from the 1970s to the 1980s, as Neumeyer's analysis begets some introspection and examination of Hindemith's systems. Hindemith, in the third volume of Craft, offers his own view of structuring his music tonally, saying that one should establish

\footnotetext{
${ }^{24}$ Neumeyer, 42.

25 Ibid, 43.

26 Ibid.
} 
the main points of the tonal progression: the beginning, the cadence (on which to a great extent depends the character and strength of definition of the tonality), and some of the more prominent and significant intermediate points, such as tonic recurrences, active tonal functions, deceptive progressions, the most distant degrees, the secondary functions, etc. ... Only thereafter do we fill in the missing elements. This manner of working is analogous not to the method of the mason ... but to that of the sculptor: it is always a complete structure which we have before us and around which we range as we work, alternately modeling in all places. ${ }^{27}$

In addition to Neumeyer's observations, Ian Kemp reckons Hindemith's

views on tonality with his theories on proportional design within his music:

Hindemith's preoccupation with the balanced formal design reflects both his quasi-metaphysical view of proportion ... His formal procedures may be classified by relating them to the two principal melodic types, the self-contained/static and the incomplete/cumulative. ${ }^{28}$

Kemp here provides a launching point for an analysis of Hindemith's tonal methods. As Neumeyer and other modern scholars have noted, Hindemith's music was largely governed by melodic influence, operating at a top-down level of melodic-to-harmonic hierarchy. In other words, the melodic content largely dictates the harmonic content, in Hindemith's own words:

The will toward intensified motion dominates the contrapuntal structure in all its aspects. The deeper this motion is to grasp, the greater the masses that must be moved, the slower and more rolling the motions. The slower waves of harmonies, moving at greater depth, follow the surface-rooted melodic intervals, which unite into lines. These waves move on the next lower, more forceful level of motion represented by the intratonal relations, which themselves feel beneath them the effective but stationary burden of the total tonality [Gesamttonalität], the last and most comprehensive concept of harmonic-melodic construction. ${ }^{29}$

\footnotetext{
27 Ibid, 45.

28 Ibid.

${ }^{29}$ Ibid, 29.
} 
Further, in Hindemith's introductory remarks to his revised song cycle

Marienleben (1948), Hindemith summarizes thusly:

The primary elements of composition (rhythm, melody, and harmony) are ... no longer placed one upon another, like building blocks, but rather each element is determined by the vision of the complete work, and in each the labor of composition proceeds from the large to the small, from the general to the particular ... Melody then does not remain confined to the explicit interval steps from each tone to the next, but is laid out in advance over longer periods, and then subdivided.

Individual harmonies are then considered important only to the extent that they take their assigned places in the unfolding of the superior harmonic principle - that of tonality.

The accompanying constructive factors of dynamics, tonecolor, agogics, and so on, are placed entirely at the service of the balanced cooperation of the primary elements. ${ }^{30}$

From these remarks, one can surmise the very structured and methodical approach that Hindemith undertook. Indeed, Hindemith's sketches show that he often mapped out the general "key area" of a work which give insight to some of his overarching tonal methods. These key areas refer to a sectional classification of pitch centers within his works, analogous to the standard concept of key within Western music. Hindemith typically shies away from using key signatures and instead writes completely chromatically. These key areas can occupy long or brief formal space, and can also be classified hierarchically. This key area hierarchy can be discerned from Hindemith's notes, as Neumeyer presents in his book, and is typically governed by length and other structural cues that I will discuss in later chapters. Key areas can include intense chromaticism, aligning with Hindemith's tonal theories, yet must ultimately preserve the given pitch class in some way, such as pedal motion or the repetition of chordal arrangements with few dissonances

${ }^{30}$ Ibid, 28-29. 
that display the primary pitch as a fundamental member of the arrangements.

David Neumeyer makes considerable attempts to distill Hindemith's theories on tonal relationships, as portrayed in his book The Music of Paul Hindemith and numerous articles. ${ }^{31}$

Cadence and transition are two closely linked topics that Hindemith writes about, although not at length. In particular, cadence is given attention in Craft, where Hindemith portrays it as a fundamental necessity of form. Hindemith writes that

[n]o doubt about tonal meaning can arise in cadences ... Here the harmonic close falls together with the formal ending. The structural tendency toward an ending in a cadence subordinates all other factors to it, while in other harmonic developments what is sought is the free unfolding of rhythm, melody and harmony. ${ }^{32}$

Hindemith's thoughts on cadence align with his views on structure and formalism. To Hindemith, and perhaps to the neoclassical idiom in general, cadential constructs are responsible for the sorts of medium-scale format delineations that define sectionality and provide a structural reference for listeners and analysts. As will be shown in later chapters, concepts of cadence and transition in Hindemith's music are fluid; true cadential points of rest are rare, and cadential/transitional structures are hallmarked by their status as phrase-ending devices that convene between key areas.

To fully consider these aspects of Hindemith's tonality and to address the overarching issue of neoclassicism, I will examine the corpus of Hindemith's sonatas

${ }^{31}$ See "Tonal, Formal and Proportional Design in Hindemith's Music," Music Theory Spectrum 9, no. 1 (1987): 93-116.

32 Hindemith, 143. 
for solo brass and piano. Hindemith's status as a neoclassicist warrants an investigation into the particulars of neoclassical structure. While Neumeyer and others have given detailed analyses of many, many facets of Hindemith's works, none yet have addressed the simple neoclassical aspect of cadence and transition. These mid-level formal structures are what give credence to Hindemith's so-called "key areas," which smack of the tonal gravity referred to by Payne. It is my hope that this document represents a foray into the scholarly exogenesis of cadence, as Neumeyer did for Hindemith's tonality in The Music of Paul Hindemith. In Chapter 2, I will lay out my analytical methods and observations on the brass sonatas that will then be applied to resultant analyses in Chapter 3 . 


\section{CHAPTER 2}

\section{ANALYTICAL CONCERNS AND METHODS}

Paul Hindemith's music has been situated in terms of tonality, both in historic and modern scholarship. Through David Neumeyer's analyses found in The Music of Paul Hindemith paired with a close reading of Craft of Musical Composition, we can clearly see the way Hindemith composes within the tonal realm; see below for an example of Hindemith's music from the compositional era concurrent with Craft that I will be discussing.

Neumeyer also makes some pertinent observations on tonal parallelisms between Hindemith's music and the earlier progenitor music from which he might borrow or adapt overarching structural indicators. And also, as noted in the previous chapter, Neumeyer acknowledges the presence and importance of transitional methods within Hindemith's music, including the cadence. However, a little-probed and integral functional aspect of Hindemith's music, as particularly exemplified by the sonatas, are the unique treatments of cadence and transition within single movements of his sonatas. These structures are paramount to our understanding of tonality and how it functions. Without the building blocks of these 
fundamental structural aspects, there is no basis for tonal musical organization in the classical construct.

These cadences and transitions fulfill similar functions to one another and, as sectional bookends that could be considered working somewhat independently, summarily display unique relationships to be analyzed separately from the melodic and harmonic content of the sonatas. As a test case for some of these relationships, I will be examining Hindemith's Sonata for Trombone and Piano (1941) and in the subsequent chapter give a careful analytical treatment of the sonatas for trumpet and tuba.

I will again draw the reader's attention to the piece I highlighted in Chapter 1, the first movement of the trombone sonata. In particular, I would like to examine this passage in Example 2.1, spanning mm. 22-29. 

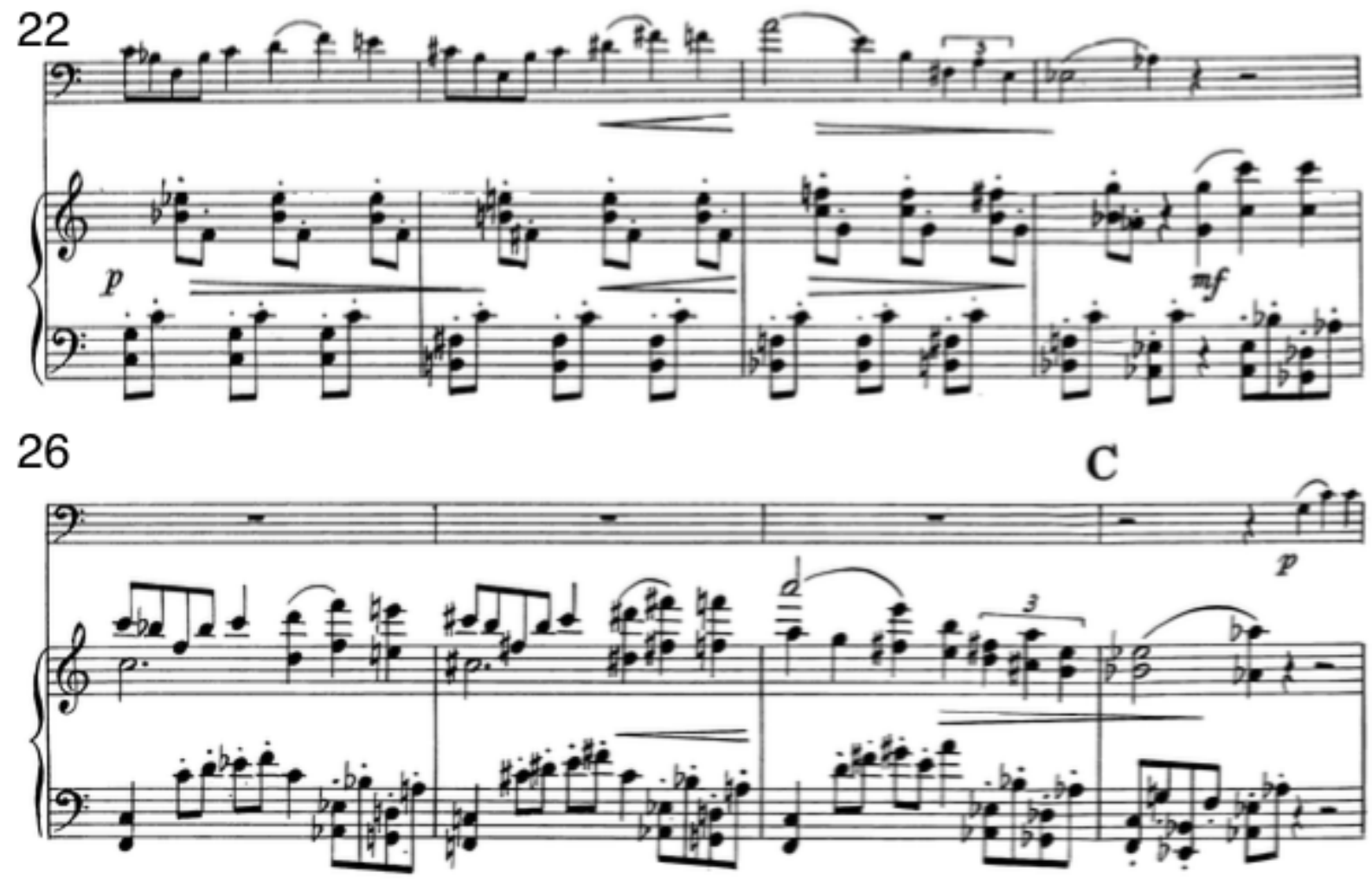

Example 2.1 Sonata for Trombone and Piano, mm. 22-29

What do these eight bars tell us? Referring to Hindemith's note sketch of the trombone sonata key areas in Fig. 2.1, this section of the music falls within the key area of C. However, the descending stepwise line that begins in $\mathrm{m} .25$ and continues thereafter draws the ear towards a different, local gravity: that of F. Two surface observations can come from examining this passage in conjunction with the key areas of the trombone sonata: that Hindemith uses key areas hierarchically, on more local and global scales that are not expressly defined in his key area sketches ${ }^{33}$, and that these key areas can be arrived at through stepwise, descending motion.

33 This relationship is expounded upon in Example 2.5. 
Another example of this occurs in the opening bars of the piece, shown in Example

2.2 .
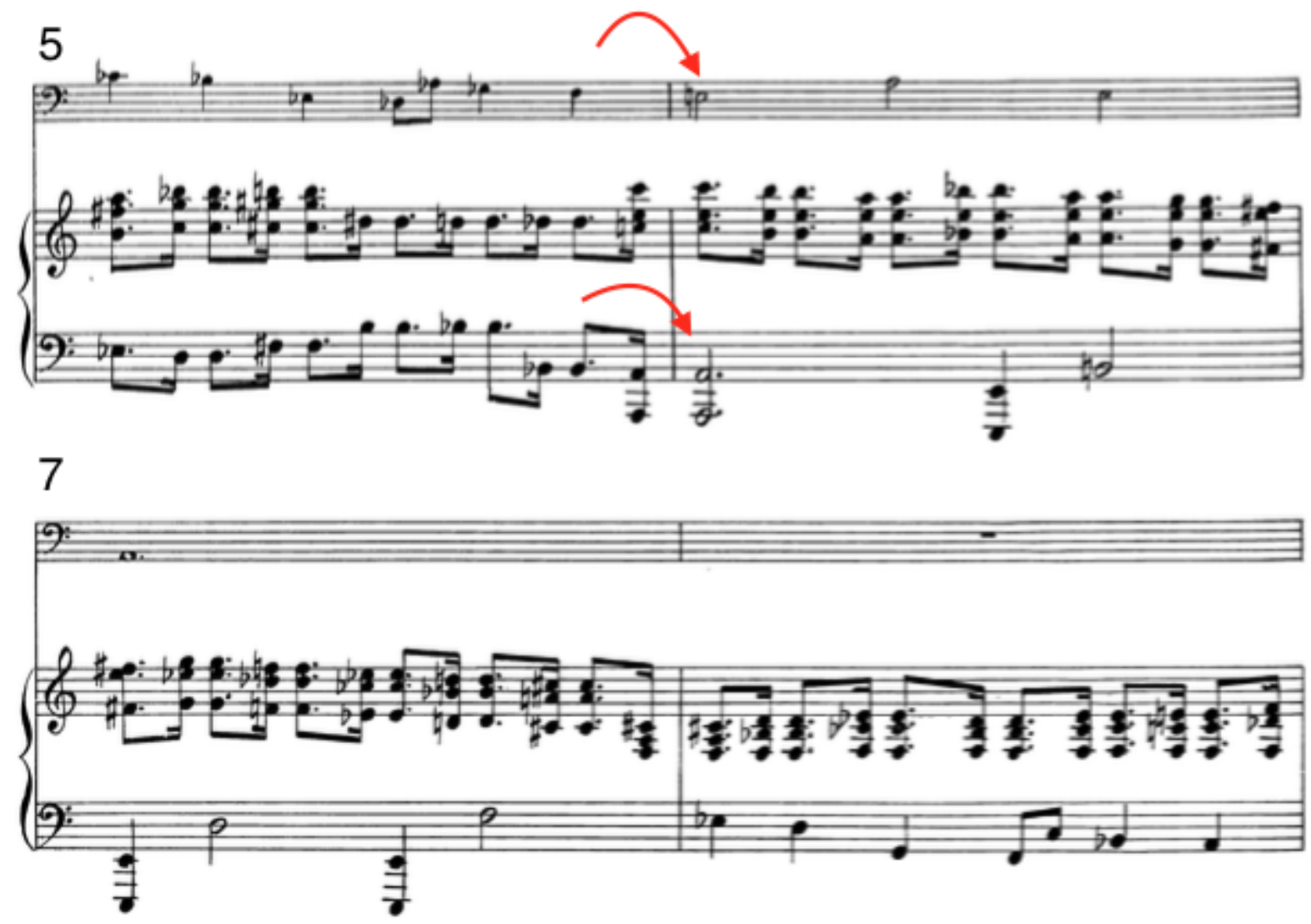

Example 2.2 Sonata for Trombone and Piano, mm. 5-8

This example shows yet another deferral of key area. Here, the specified area is F, yet Hindemith moves to a clearly A-type area; note the quasi-I-V-I gesture in the trombone part as well as a mantling of the primary theme in the piano within the new key area of A. Yet, Hindemith does not mark it on his global key map.

Speaking globally and looking at Hindemith's tonal map, the primary and secondary theme areas are delineated, with F moving to key area $\mathrm{C}$ echoing the 
tonic-dominant motion expected in movement from primary to secondary thematic areas. Preceding the transition, there is a local shift to B in bar 19, displayed in the bare octaves in the piano and trombone parts in Example 2.3. But notice how Hindemith then transitions to a key area of C. The descending, alternating motion between half step and major third is broken by a half step, descending fifth, circled in red on the example.

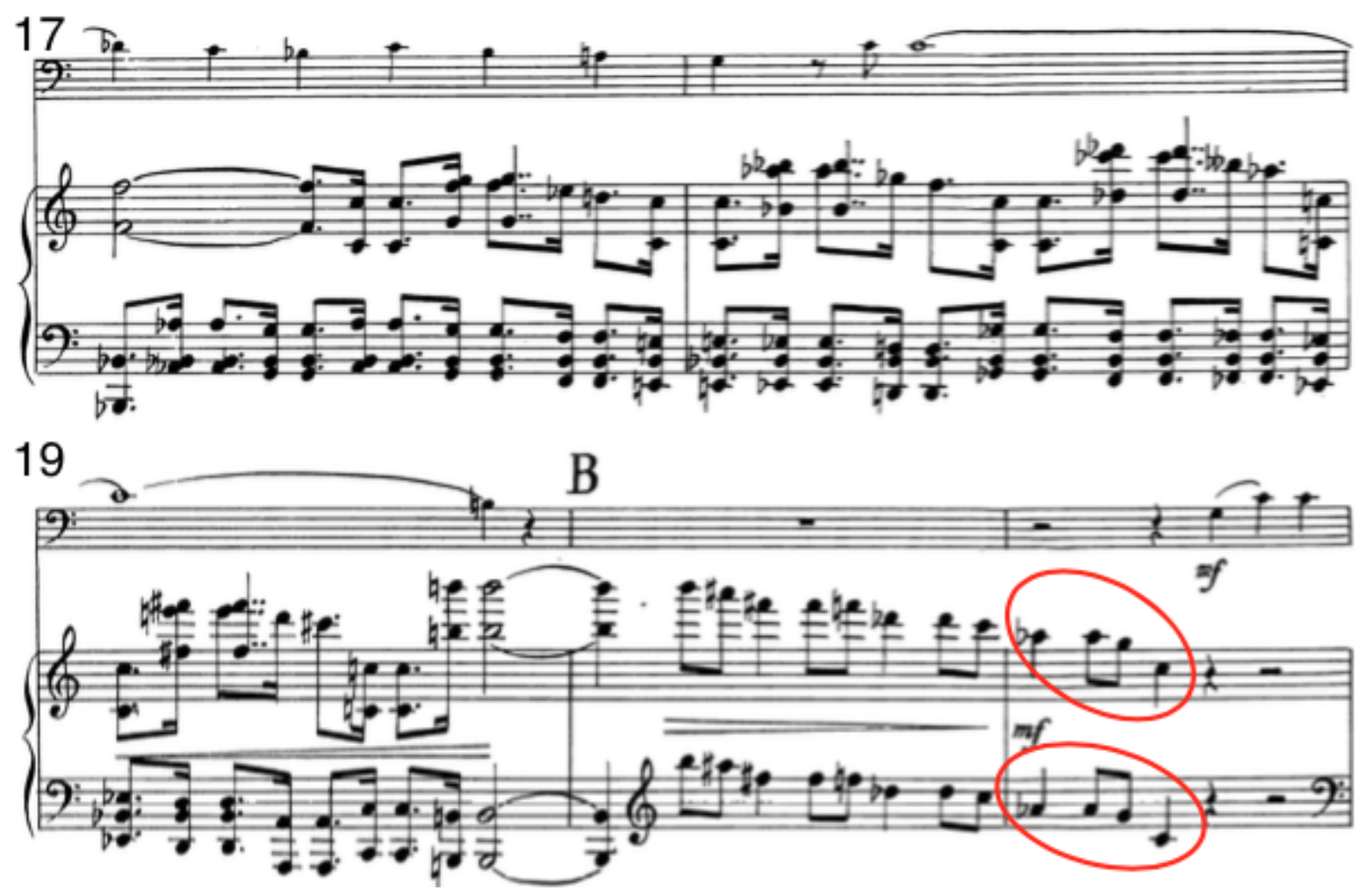

Example 2.3 Sonata for Trombone and Piano, mm. 17-21

These examples show transitions between key areas, but what is Hindemith doing to achieve these transitions? What are the devices employed to bring about transition or cadence, such fundamentally integral structures to the classical realm, as understood through Hindemith's neoclassical mantle? 
To provide some context within the classical idiom and regarding the formal architecture of the piece, I will look at similar formal constructs as described by William Caplin in his book Classical Form. Though Caplin firmly bounds his analyses within the classical period, the analytical facets he discusses may be used as a model and point of reference for Hindemith's sonatas and the likewise formal structures that Hindemith uses to frame them. Similarly, particular function of thematic and motivic ideas within Hindemith's sonatas display traits similar to those found in Hepokoski and Darcy's Elements of Sonata Form, which will also inform and frame this analysis.

Caplin's formal constructs can be construed as similar due in a large part to Hindemith's inherent neoclassicism: although the tonal content of the sonatas is Hindemith's typical neotonality, the sonatas themselves are not neo-formal; even a perfunctory look will reveal that they bear formal similarities to the archetypical sonata form. Although clearly referential to the widely understood sonata form trope, I would like to bring the reader's attention to the fact that this movement is also a demonstration of a frequently used Hindemithian form trope. Borrowing from Hepokoski and Darcy's seminal Elements of Sonata Theory, there are a few functions that bear examination. As a corollary, Hepokoski and Darcy's graphic explaining the initial elements of sonata form is given below in Example 2.4. 


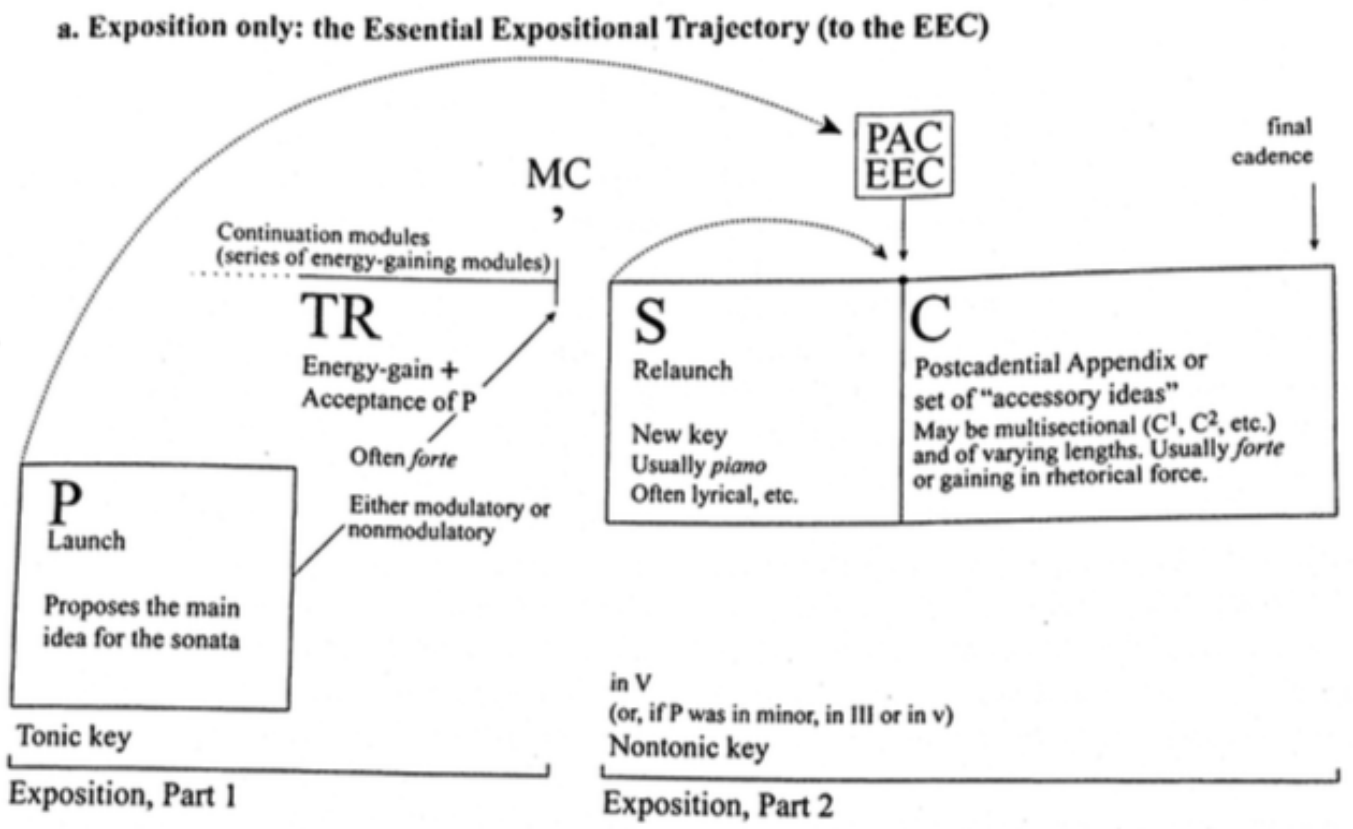

Example 2.4 Essential Expositional Trajectory, from Elements of Sonata Form ${ }^{34}$

In the trombone sonata, the restatement of the primary theme $(\mathrm{P})$ module acts as a launching point into the transition (TR) module; the medial caesura (MC) is brief, and there is a restatement of $(\mathrm{P})$ after being presented in the solo instrument part.

This form trope appears throughout Hindemith's brass sonatas as well as in some of his other sonatas. Although fundamentally similar to traditional eighteenthcentury sonata form, there are some prominent differences. The leading indicator of this form trope include an initial melodic statement from the solo instrument, typically 8 to 12 bars in length, followed by a brief restatement of the melodic theme

${ }^{34}$ James Hepokoski and Warren Darcy, Elements of Sonata Theory (Oxford University Press, 2006), 17. 
in the piano part. These thematic resurgences are employed both inter- and intraphrasally. For instance, Hindemith employs a two-bar elision between the end of the initial thematic onset in the trombone and the thematic resurgence in the piano in measures 4 and 5, seen later in Example 3.1. The trombone sonata is unique in its repeated usage of this intraphrasal thematic resurgence. As a general formal note, the exposition and development in this movement are quite lengthier than the recapitulation, which is contrary to some traditional formal practices. The recapitulation is a brief 12-bar restatement of the initial theme in what might be construed as the dominant, as opposed to the expected return to tonic.

Indeed, within his sonatas Hindemith displays goal-oriented tonal schemes that are obfuscated by the music's inherent non-diatonicism but ultimately rely upon the sonata principle. We may understand this paradigm within Hepokoski and Darcy's conceptions of the various task-related roles to the components of sonata form:

[The exposition's] harmonic task is to propose the initial tonic and then, following any number of normative (and dramatized) textural paths, to move to and cadence in a secondary key. ... The exposition's rhetorical task, no less important, is to provide a referential arrangement or layout of specialized themes and textures against which the events of the two subsequent spaces-development and recapitulation-are to be measured and understood. We refer to this layout as Rotation 1 or the expositional rotation..$^{35}$

We can also understand in broad terms that Hindemith adheres to these elements while imposing upon them a sort of twentieth-century filter. Elements both structural and formal may not align exactly with the prototypical eighteenth-

35 Ibid, 17-18. 
century sonata form; Hindemith eschews neat sixteen-bar phrase formatting, reflective of the evolution of form, and his hierarchical application of Series 1 and Series 2 systems in tonal schema likewise represent a development of tonality. While neoclassicism is a prominent element and perhaps the crux of all of Hindemith's work with sonatas, a broader discussion on this topic will follow in Chapter 4.

Moving from a large-scale to mid-level investigation, cadence and transition are both delineators that occupy the terminal formal space at the ends of phrases, and are demarcations of medium-scale formal functions. As Hindemith deals in the typical classical formula of sonata form within his sonatas, it is appropriate to examine cadential and transitional figures with regards to traditional formal constructs. Cadence, in regards to Hindemith's music, is similar to its traditional counterpart yet exhibits some differences. In these analyses, we can best understand "cadence" to refer to musical full stops that mark the end of a key area. Transition, similarly, refers not specifically to the Hepokoski and Darcy model of (TR) modules, but the simpler motion between key areas that are not achieved by a musical full stop; in short, cadence is a static sectional demarcator and transition is a dynamic, moving one.

In Classical Form, William Caplin dissects various cadential formulae from the classical literature and provides some contextual scholarship. Caplin notes the importance of cadence within the classical idiom:

Music in the classical style is often characterized as highly goal directed, and many of the principal goals in a composition are the cadences marking the ends of themes and theme-like units. 
Identifying the cadences is thus a critical objective of any formal analysis. ${ }^{36}$

As Caplin's "critical objective," cadence becomes a central facet of his

discussion of sentence structures within classical music. In this light, he summarily

identifies three typical usages of the term cadence. Of most relevance to the

discussion at hand is his second sense of cadence, which

refers to the time span leading up to [the] point of [cadential] arrival, that is, the idea or phrase in the theme that communicates to the listener that "the cadence" is forthcoming. This passage of music can be said to have a cadential function because it creates the requisite conditions for thematic closure by means of specific harmonic, melodic, and phrase-structural devices. ${ }^{37}$

These devices, forms and functions are likewise present in Hindemith's tonal

music, which I will later demonstrate and elucidate. Especially applicable to

Hindemith's work is Caplin's observation on the cadential progression:

the cadential progression supports a distinctly new melodic idea of marked cadential character, a melody that is clearly different from the preceding material associated with an exclusive continuation function ... frequently, though, the cadential idea grows directly out of the melodic-motivic content of the continuation... ${ }^{38}$

Although Caplin here is describing melodic change, a similar

transformational aspect occurs throughout Hindemith's sonatas: overarching harmonic change displayed and delineated through countermelodic bass motion.

Another feature that can be applied to Hindemith that Caplin relates is the idea of "form-functional fusion" in regards to cadence. Writing specifically about sentence structure, Caplin states

36 William E. Caplin, Classical Form (Oxford University Press, 1998), 42.

37 Ibid, 43.

38 Ibid, 45. 
... the second half of the eight-measure sentence combines continuation and cadential functions into one four-measure phrase. The presence of two different functions in a single group can more technically be termed form-functional fusion ... Not only does the phrase begin with continuation function, but also the processes of fragmentation, harmonic acceleration, and increased surface rhythm often carry on into the cadential material. ${ }^{39}$

Transition is another fundamental aspect or agent of change acting throughout the sonatas that has similar formal ramifications in the classical literature. Transitions are a prominently analyzed feature within Caplin's book; he outlines specific transitional functions within various forms. Caplin highlights the usage of transitions as agents of disruption:

At the heart of the tonal drama in the exposition of a full movement form ... lies the conflict between the home key and its rival subordinate key ... the transition ... serves to destabilize the home key so that the subordinate key can emerge as a competing tonality in the exposition. In addition, the transition loosens the form established by the tight-knit main theme, imparts greater rhythmic continuity and momentum to the movement and ... liquidates the characteristic melodic-motivic material in order to "clear the stage" for the entrance of the subordinate theme. ${ }^{40}$

While Hindemith does not use keys in the same manner as his classical predecessors, he does use a tonal system that emphasizes linearity; Hindemith tends toward "competing" motivic lines and countermelodies, not of a particular key origin, but more linear and less broad-scale than the type espoused by the music Caplin is describing here.

It is important to note that should be grouped together here because within Hindemith's music they take on a similar function of propelling the music into a different tonal area, as related previously. Rare is it that the conclusion of a cadence

${ }^{39}$ Ibid.

${ }^{40}$ Ibid, 125. 
or the trappings of a transition results in the music remaining in the same key area. This is a phenomenon that exists within both medium-scale key area relations as well as smaller-scale, inter-key movement. These two functional demarcations are so closely linked, and within key area analysis act so similarly to one another, that they should be considered two sides of the same demarcating coin.

As cadence and transitions are closely linked due to their nature of tonalityclosing or theme-closing function, Hindemith often closely linked the ideas of demarcation and tonality in his own writings. In The Music of Paul Hindemith, David Neumeyer writes:

Hindemith attached great importance to the cadence as the point at which harmony and melody within a phrase or period intersect with the structural forces of tonality and form. His conception of cadence, however, is not a revival of the old notion of point of rest. To Hindemith, the cadence is first of all a force of binding; joining melodic activity firmly to the harmonic-tonal basis, and harmonic-tonal patterns to the formal structure. ${ }^{41}$

Neumeyer notes that, much as many other aspects of his music, Hindemith's cadential techniques matured in accordance with the development of his compositional style and tenets as discussed in Craft. ${ }^{42}$ Neumeyer also makes many pertinent observations of cadential construction, ${ }^{43}$ including the presence of goal tones and tendency tones as pertaining to Hindemith, but cadential approach is not a well-tapped issue in his analyses. Indeed, much of the scholarship surrounding Hindemith that has been heretofore discussed gives only a passing mention of cadential functions; generally, they espouse that cadences exist, that they broadly

${ }^{41}$ Neumeyer, Music of Paul Hindemith, 44.

42 Ibid, 240.

43 Ibid. 
follow melodic lines, and that there is a general sense of increased rhythmic activity as the lines approach the cadential figure.

Likewise, Hindemith treats the aspect of simple transition similarly, detailing this in Craft that deals with local transition and progression is his discussion of stepprogressions. Hindemith says that

Every melody consists of prominent tones and subordinate ones. On the one hand, the roots of the little chord-groups in the melody-that is, of the "body" of the melody - must be considered the more prominent tones. ... The primary law of melodic construction is that a smooth and convincing melodic outline is achieved only when these important points form a progression in seconds. ${ }^{44}$

Extrapolating from Hindemith's skeletal of "progression in seconds" comes a sense that, for Hindemith, the more Schenkerian or reductivist approach is one of at least compositional significance, if not analytical significance. One can point out these step progressions within Hindemith's music, and as an act of transition they are frequently employed to navigate disparate key areas.

The defining features that surround the navigation of disparate key areas are less pronounced in Neumeyer's analysis and even in Hindemith's own Craft, where the main focus is large-scale formal aspects and the pedagogical implications and adaption of the methods at hand, respectively. I do not wish this document to turn into a critique of Neumeyer's or any other analyst's work, but current scholarship stops just short of the integration of studying the important formal ideas of the medium-scale structures I have previously identified.

${ }^{44}$ Hindemith, 193. 
David Neumeyer in his book and Dorothy Payne in her dissertation have given numerous analytical readings of Hindemith—dealing with tonality, proportionality, rhythmic and hypermetric concepts, counterpoint and intertextualism-yet a heretofore unexamined aspect of his music is how Hindemith compositionally maneuvers between disparate key areas. Hindemith's wind sonatas provide ample and mostly untrodden analytical ground for this endeavor; some of Hindemith's most popular works are probably his song cycle Das Marienleben, opera Mathis der Maler and the keyboard studies of Ludus Tonalis, while the sonatas remain somewhat neglected. Due to their inherent pedagogical or instructional nature, they reflect a primary, fundamental aspect of Hindemith's compositional ethos. The brass sonatas in particular are notable for the compositional methods that Hindemith uses in each to navigate these various tonal constructs.

While they were written in a close compositional period, they show some similar medium-scale idioms and are written with such stylistic appropriateness that they could be grouped together and thought of as a collection. ${ }^{45}$

To begin to distill localized functions in the brass sonatas, a medium-scale analytical method will be used that reveals the relationships between Hindemith's previously cited conceptions of key areas and movement between these areas.

Referring back to Examples 2.1, 2.2 and 2.3 at the onset of this chapter, one can see a transition between distinct key areas through this music. The prominent feature within these two sections, and the overarching analytical concern through

${ }^{45}$ Many album releases have followed this classification; see Paul Hindemith, Sonatas for Brass and Piano, Glenn Gould with members of the Philadelphia Brass Ensemble, Sony 52671, 1992, CD. 
this document is the presence of intervallic gestures that denote or precede a tonal shift. These shifts can occur in either transitions or cadences, both of which are closely linked. It should be noted that the presence of de facto cadence within Hindemith's music is relatively rare, either in outlined or implicated dominant-tonic motion. This contextual ambiguity in the ends of phrases - so often muddled by the inclusion of Hindemith's characteristic quartal or secundal harmony-means that the powerful impetus of cadence is largely lost until the rare moment that it is not, making the presence of true cadential figures rare and memorable, and often approached as such from a structural standpoint. ${ }^{46}$

To better understand how cadential and transitional material functions within the brass sonatas, the overarching textures within these sonatas must first be discussed. The sonatas contain a general three-voice texture: solo instrument, piano right hand (RH) and piano left hand (LH). A cursory scan of any of these pieces will reveal this textural setup to be present, although there do exist occasional aberrations in which all three of these voices might not be occurring in combination in the name of textural variety. Occasionally, two of these voices might also conjoin to represent one coherent musical idea-for instance, piano RH and LH might combine to act as a singular melodic force with reinforced harmonic points, or the solo instrument might combine with piano LH. These ideas and the corresponding voices can then be inferred to occupy primary, secondary and occasionally tertiary musical space. An interesting exception that I will discuss in the next chapter is the tuba sonata, in which the solo instrument often occupies a secondary role to the

46 See Neumeyer, The Music of Paul Hindemith, 56-60 for corollary information on Hindemith's theory of fundamental bass. 
piano throughout the work. In general terms, Hindemith employs a dense, contrapuntal language that includes intense chromaticism that is structured tonally.

This motioned counterpoint allows for the presence of very active lines throughout all levels of musical space. Within these sonatas, there exist three primary levels of musical space:

1. Primary level; contains the main melodic idea (typically solo instrument but occasionally piano $\mathrm{RH})^{47}$

2. Secondary level; contains subordinate counterpoint to the main melodic idea. Less motion, filling in vertical tonal space

3. Tertiary level; fundamental bass motion, longer note values

Basic, fundamental intervallic gestures that predicate certain tonal shifts typically occur in tertiary or secondary musical space; they are subordinate to the main theme and act primarily as a contrapuntal or otherwise non-primary musical force-a sort of underlying motion potentially obscured by higher levels of musical space. Although these phenomena occur typically in the lowest voice of the texture, they can occasionally be found in inner voices or topmost voices of texture. The greatest hallmark of these gestures is their transversal of disparate key areas, although they might function at levels more local or global than the ones Hindemith might have originally designated in his original sketches. There are other shared aspects within these sonatas as well, but the presence of these preceding intervallic gestures is the most important to my analyses. The example below from mm. 20-27

${ }^{47}$ This trope is subverted in the Sonata for Tuba and Piano. 
of Hindemith's 1941 Sonata for Trombone and Piano shows such intervallic gestures in action.

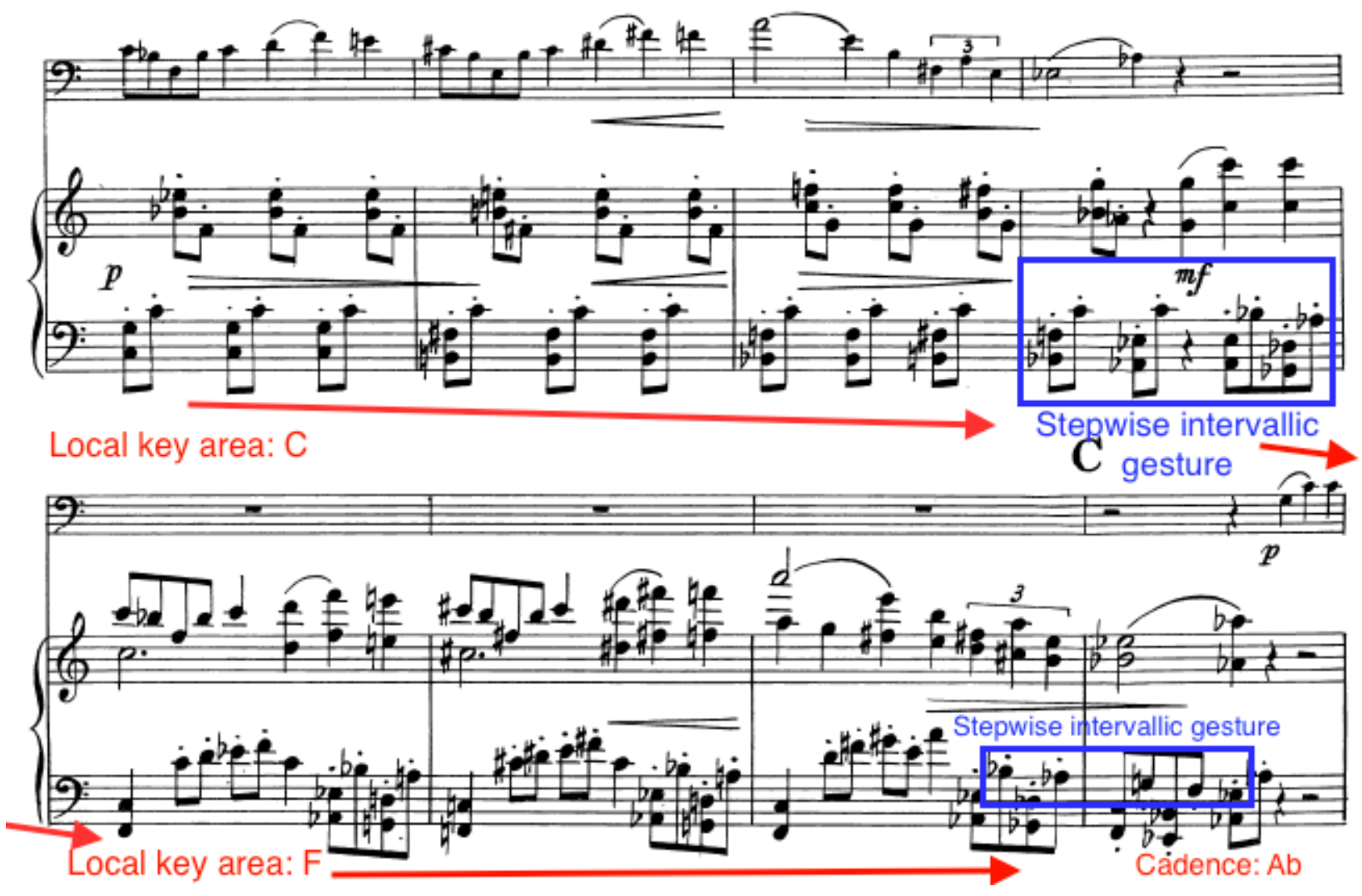

Example 2.5 Sonata for Trombone and Piano, mm. 20-27, annotated

A cursory glance displays the presence of two primary lines of musical texture: the trombone occupying primary space, and the piano $\mathrm{LH}$ and piano $\mathrm{RH}$ combining to occupy secondary space at the onset. However, as the roles shift and the piano RH takes over the brunt of the melodic load, piano LH makes a stepwise descent from $\mathrm{Bb} 2$ to $\mathrm{F} 1$. This descent can be represented by finding the initializing tone and counting the half-step intervallic increments within the descent: $(-2,-2,-$ 
1). ${ }^{48}$ This descent propels the music forward into a new local key area of $\mathrm{F}$, and a similar stepwise descent of $(-2,-1,-2,-2)$ occurs in mm. $26-27$ that highlights the local key area of Ab, a rare instance of a skeletal V-I of sorts. As shown in mm. 26-27, the stepwise descent does not always have to occur in the lowest voice; inner voices can also provide this function. An alternate reading of the primary bass line $(-2,-1,-$ $2,+5$ ), observing the quintal descending harmonies, would also fit this passage, but the line chosen-as in this case-should ultimately be governed by which one best fits the resultant local key area. The $(-2,-1,-2,-2)$ reading better highlights the crossing of voices between the tertiary and secondary musical space.

I have termed this phenomenon of cadence/transition interphrasal terminal descent ${ }^{49}$ or ITD. The related descending stepwise motion acts as a catalyst to propel the music into a different key area; hence, I term these short pitch collections motivic catalysts, or MCs, that herald the terminal descents. For instance, the motivic catalyst $(-2,-2,-1)$, starting on $\mathrm{Bb}$, catalyzes an interphrasal terminal descent of $\mathrm{C} \rightarrow \mathrm{F}$. These gestures could also be represented with pitch notation such as (Bb, Ab, Gb, F), yet this representation doesn't immediately capture the essence of stepwise descent as the positive and negative integers referring to half step distance do.

While the motivic catalysts are generally stepwise and descending, the resultant key area motion is not necessarily stepwise. The general rule I have found

\footnotetext{
${ }^{48}$ The interpolation of half steps and whole steps, including the terminal half step, is structurally significant and one of the most common demarcators in Hindemith's brass sonatas. Furthermore, the initiating tone within these stepwise patterns must be considered contextually.

${ }^{49}$ Bold, italicized terms are defined in the appendix near the end of this document.
} 
is that the terminal half-step (-1) motion is perhaps the strongest of all motions to new key areas; descent of whole step and leaps beyond that are all generally indicative of weaker cadential points and herald key areas that have less structural significance than those preceded by half-step motion, which will be shown in the resultant analyses. While Hindemith is rarely found to use leading tones as typically understood, the presence of this falling tone half-step descent is indicative of a similar harmonic, melodic and structural weight within Hindemith's tonal structures.

In Schenkerian terms, the motivic catalyst is definitely a foreground phenomenon, though it points towards larger, broader (middle-ground and background) tonal implications, and the general phenomena of transition and cadence occurs at the medium-phrasal level. ITD can be understood as how Hindemith negotiates disparate key areas; MCs can be understood as the why, or perhaps the how of the how. The discovery of hidden, analytically rich material in previously studied music only serves to enhance and strengthen the understanding of the underlying compositional and musical processes and informs our structural understanding of Hindemith's neoclassicism.

The following chapters will show these gestures in various forms throughout the brass sonatas through an in-depth analysis of the first movement of each sonata. As the first movements of these sonatas typically display Hindemith's take on the traditional sonata form, the neoclassical formal structure allows a better template upon which to observe these cadential and transitional phenomena taking place. 


\section{CHAPTER 3}

\section{BRASS SONATA ANALYSES}

Now that some of the rigeurs of some overarching analytical methods, new analytic structures, and their quantifications have been related, I will utilize these tools in an analysis of four works by Hindemith. The first movements of these pieces, in the classical tradition, exhibit sonata form. Through this analysis, I will highlight, analyze and situate transitional and cadential structures within Hindemith's music, framed through the first movements of his four sonatas for the orchestral brass and piano:

1. Sonata for Trumpet and Piano, 1939

2. Sonata for Horn and Piano, 1939

3. Sonata for Trombone and Piano, 1941

4. Sonata for Tuba and Piano, 1955

The brass sonatas are situated within the post-Mathis der Maler period, which David Neumeyer points to as a more mature, Craft-influenced compositional time for Hindemith. Although the pre-Mathis music is leaner and more contrapuntal in the idiom of Hindemith's neue Sachlichkeit, the majority of the instrumental 
sonatas are written in the post-Mathis period and reflect a more refined application of Hindemith's own harmonic and musical theories. This, combined with the inherent pedagogical application of these works, provides a clearer insight to the intrinsic values of Hindemith as a composer, neoclassicist and pedagogue.

The first three works present a closely grouped historical corpus, and the tuba sonata will serve to show some development of Hindemith's cadential and transitional methods in his later period. The horn sonata presents additional challenges to analysis, which I address in a subsequent chapter. Not only do the brass sonatas exemplify the specific cross-relational cadence and transition functions I will be discussing, but they were also written on the backdrop of the release of Hindemith's Craft of Musical Composition. Alongside a reading of Craft, one might then view these brass sonatas as Hindemith's theories made practice. It is not the purpose of this analysis to hold Hindemith's music up to the standards espoused in $\mathrm{Craft}^{50}$; rather, I seek to expound upon Hindemith's theories and find, classify and elucidate ways in which Hindemith deals with transitional and cadential elements within the sonatas. One can therefore read these analyses as supplemental to Hindemith's Craft theories, and not necessarily oppositional. I will structure my analyses to include formal analyses, tonal readings of key areas as espoused by Neumeyer, and an analysis of cadential/transitional phenomena.

These analyses will reveal some of the overarching structural similarities between the sonatas and delve into Hindemith's conception of key areas while

\footnotetext{
${ }^{50}$ Neumeyer makes note of the malleability of the strict rules found in Craft as evidenced by Hindemith's divergence from these ideals in the 1930s and 1940s; see Neumeyer, The Music of Paul Hindemith, 30-34.
} 
addressing hierarchical concerns. I will then apply my own theories and observations on cadential and transitional elements within medium-scale structures within these pieces by classifying and identifying instances of interphrasal terminal descent and the preceding motivic catalysts.

The following section takes an in-depth look at the sonatas using the methods detailed in Chapter 2. Although each of the following sonatas provide some analytical insight to Hindemith's music, I will begin with the Sonata for Trombone and Piano, which was given a cursory examination as a test piece for cadential/transitional phenomena in the previous chapter. As previously detailed, the trombone sonata proceeds through several related key areas, which makes it easier for the listener (and reader) to discern some of the overarching tonal concepts, especially in reference to interphrasal terminal descent and the related motivic catalysts that precede them.

\section{Analysis I: Sonata for Trombone and Piano (1941)}

While there are formal similarities between the movements, in the case of the trombone sonata there remains a more diverse palette of key areas to examine by looking at only the first movement. Figure 3.1 below is Hindemith's own key-area sketch of the first movement of the trombone sonata, spanning nine key centers of various hierarchies that are implied by note head size..$^{51}$

51 To contrast this wide range of tonal centers, the second, third, and fourth movements only span six key areas combined. 


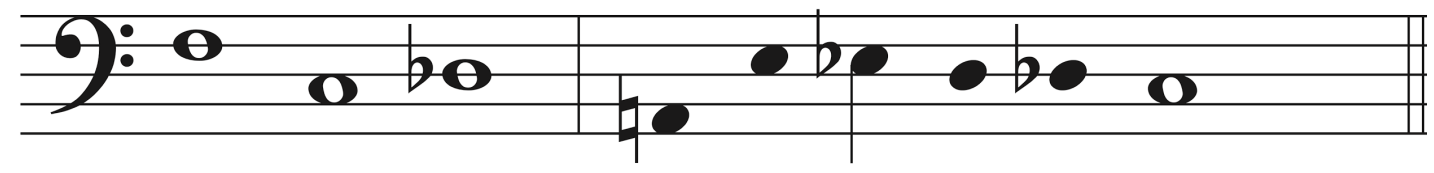

Figure 3.1 Hindemith's sketch of Sonata for Trombone and Piano, mvt. $1^{52}$
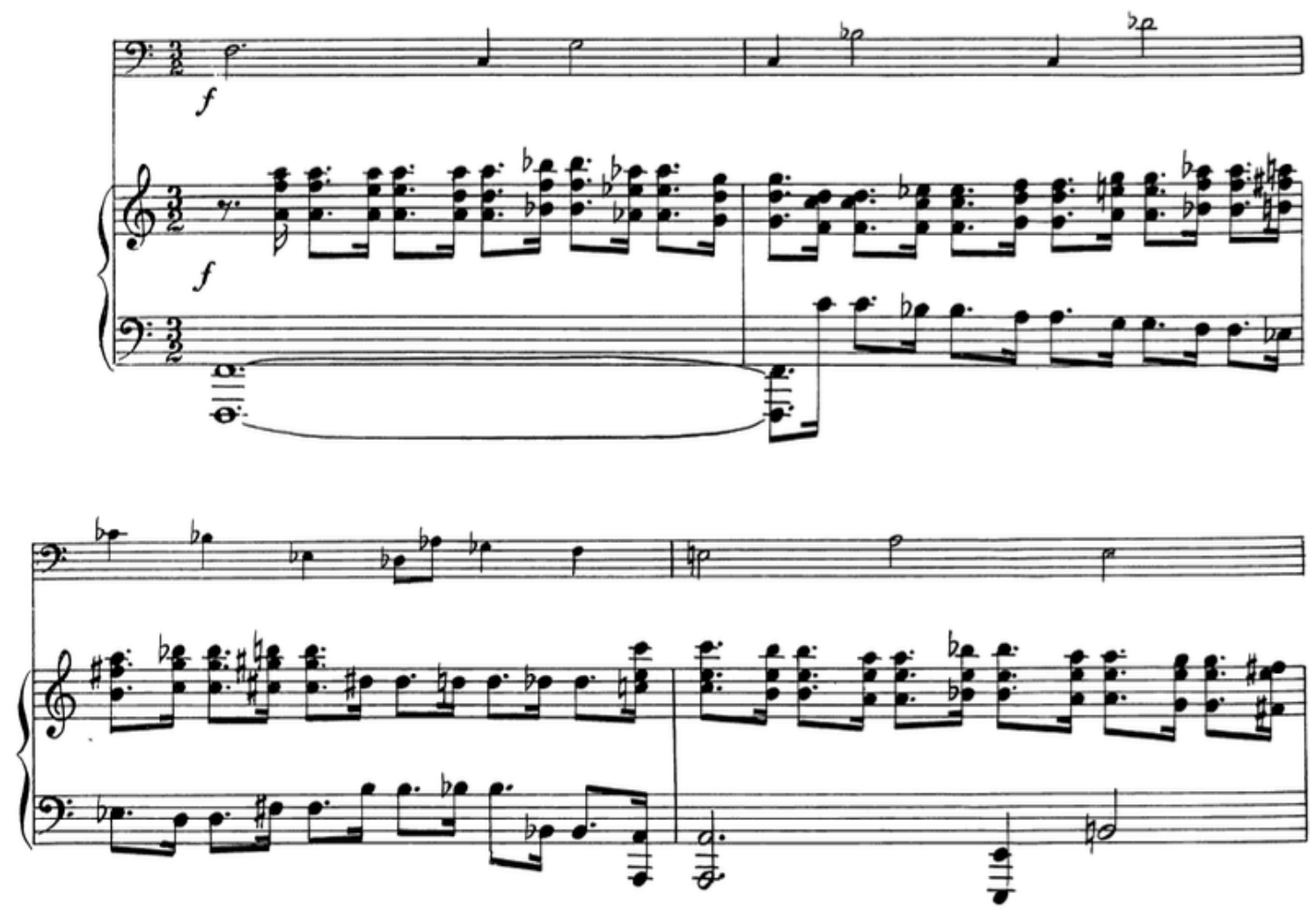

Example 3.1 Sonata for Trombone and Piano, mm. 1-4

In this movement as a whole, Hindemith presents a formal scheme that is readily accessible and discernible to the listener, with clear demarcations of exposition, development and recapitulation. Examples 3.1, 3.2 and 3.3 below show these sectional divisions. The exposition commences in Example 3.1, with the primary theme in the trombone.

52 Neumeyer, Music of Paul Hindemith, 213. 
Example 3.2 shows a rare cadence in $\mathrm{Db}$ at bar 48 , marking the end of the exposition and the initialization of the development section. The trombone initializes a move from the key area of Db to A in bar 49.
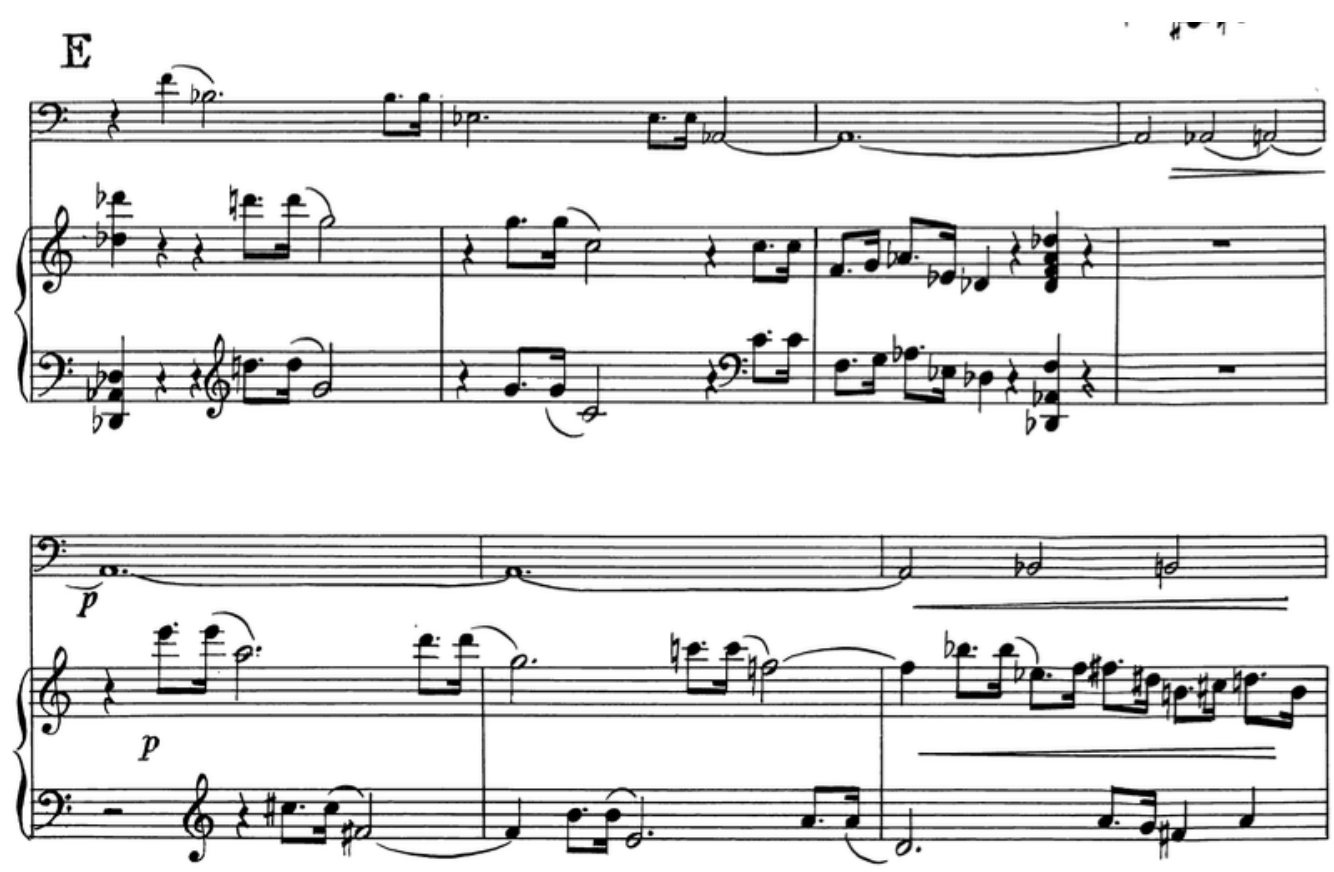

Example 3.2 Sonata for Trombone and Piano, mm. 46-52

Example 3.3 shows at bar 72 a return to the initial material as the primary theme at rehearsal letter $\mathrm{H}$, marking the recapitulation. 

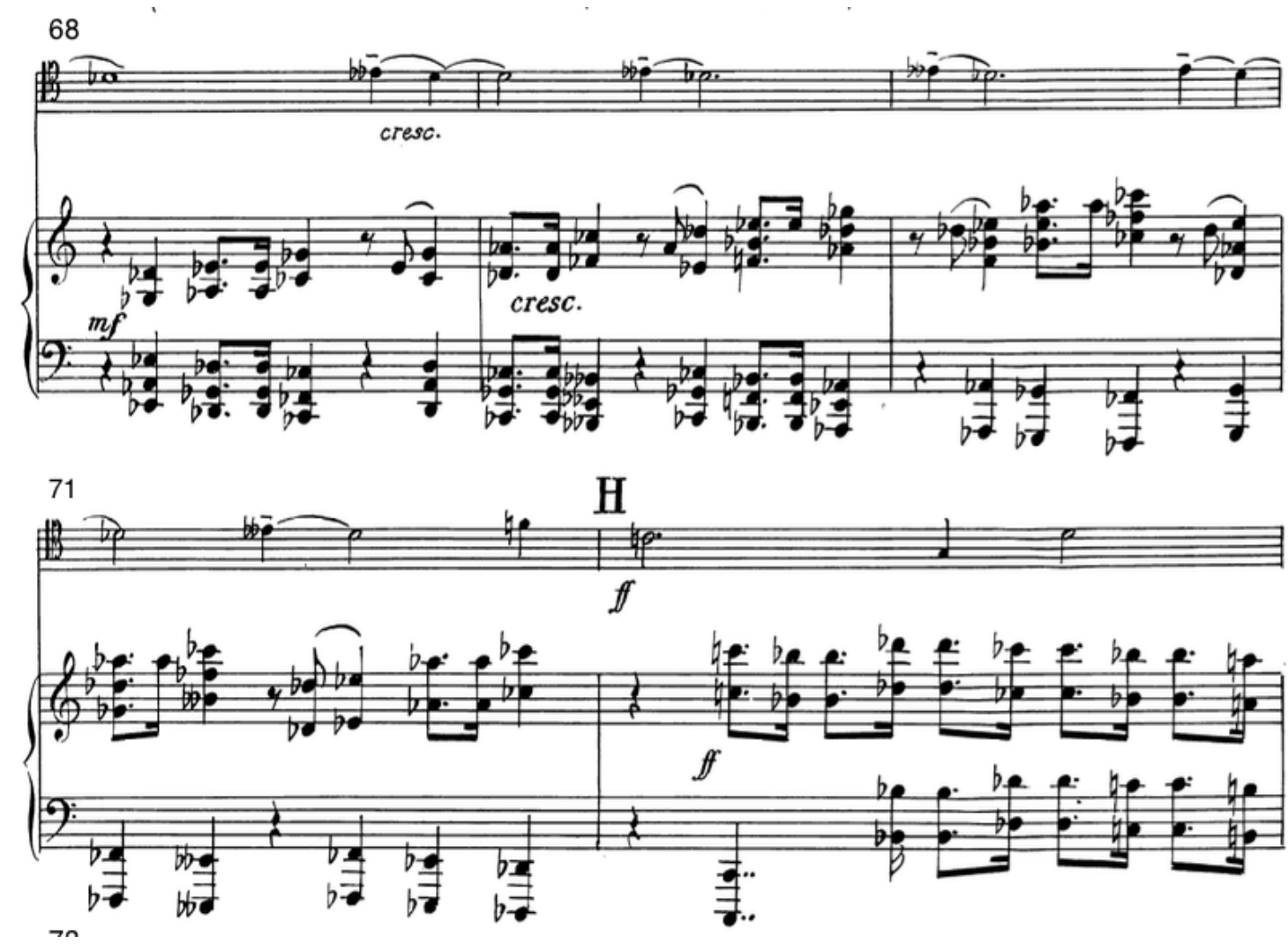

Example 3.3 Sonata for Trombone and Piano, mm. 68-72

The regular formal articulation of the movement contrasts the neo-tonal environment within which Hindemith situates the musical material, as seen in the key area graph. Through this movement, the listener can observe Hindemith navigating and negotiating the goal-oriented nature of sonata form and its various mutable tonal components with his distinctly tonal style. As the first movement of the trombone sonata exemplifies sonata form, it of course has the functional formal sections of exposition, development and recapitulation that one would expect and which are displayed in the phrase diagram in Fig. 3.1 below. This is a close approximation of the classical sonata form trope, but operating as a neoclassicist, Hindemith does not adhere to all of the typical key-relation schema one would 
expect to find in the sonata paradigm; namely, writing the recapitulation in the “dominant," C.

While the exposition and recapitulation explore two primary key centers (F and C), the development section presents a much more chromatic tonal map, aligning with Hindemith's non-diatonic compositional method, and Hindemith also makes frequent use of transitional piano motives.

The overall key scheme of this work is F-centric, yet culminating on C with a myriad of other key relationships interspersed. However, as Hindemith shows, not all key areas are created equal. As note head size directly correlates to structural importance of key area, the overarching scheme might be reduced to a more fundamental map of $\mathrm{F} \rightarrow \mathrm{C} \rightarrow \mathrm{Db} \rightarrow$ (development) $\rightarrow \mathrm{C}$. A map of the key areas of the piece in regards to their formal place is given below in Figure 3.2.

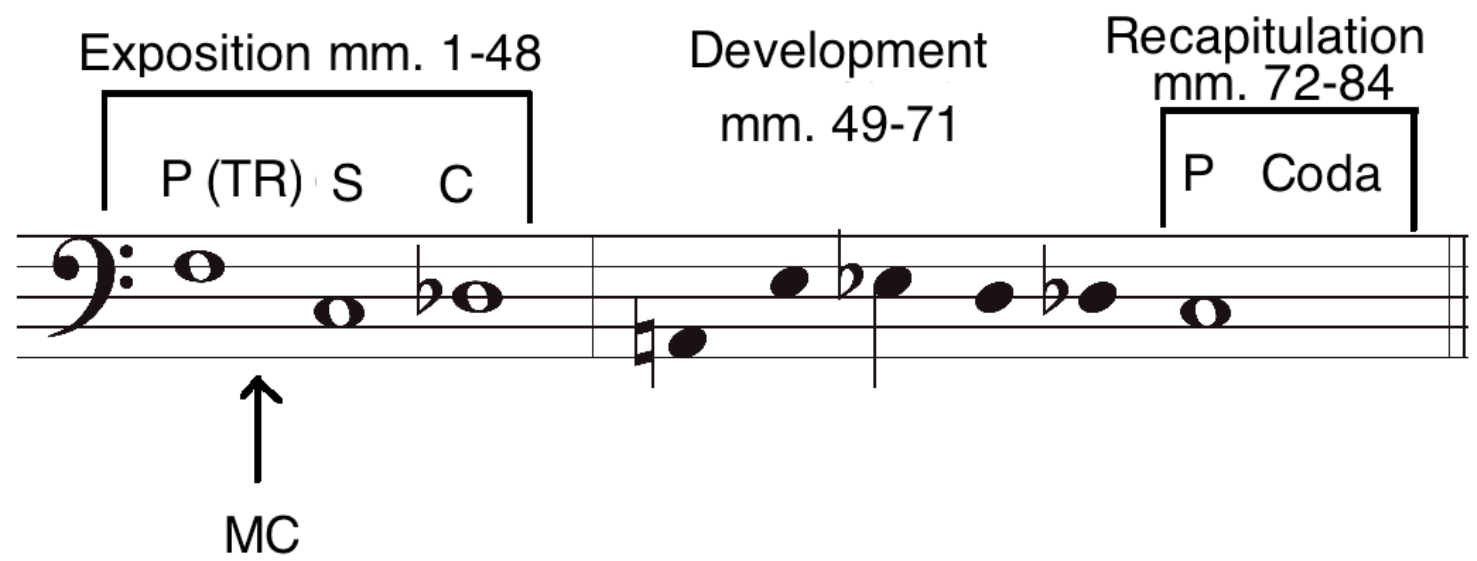

Figure 3.2 Trombone Sonata key areas and formal labels

The first major transitional elements come into play between the expositional key areas of F and C, in bars 17-19. This demarcation is made most 
prominent by a complete collapse of the melodic material as both the trombone and piano parts converge through $(-1)$ bass motion into $B$, a tritone away from the nominal key area of F. As this occurs, the listener is treated to a transitional motif contrived of repeated descending third figures, $(-1,-4)$. However, this descending third motion is broken up by a final $(-1,-7)$ motivic catalyst that transitions the music into the new key area of $C$. This is therefore an example of a $(-1) /(-1,-7)$ antecedent/consequent ITD pattern, containing two MCs that lead to a new key area. This motion, highlighted in red, is shown in Example 3.4.

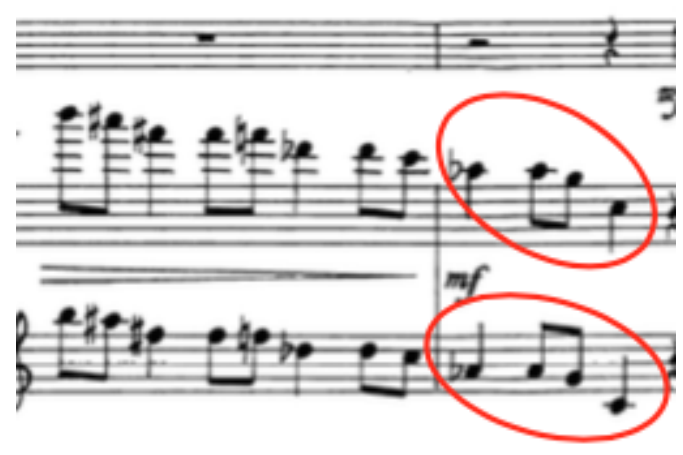

Example 3.4 Sonata for Trombone and Piano, mm. 18-19

According to Hindemith's key area sketch, the next large-scale tonal transformation occurs between the key of the second theme, C, and the first key of the development, Db. By interpreting the note head size of the sketch as referring to a tonal hierarchy (refer to Fig. 3.1), this is a major tonal shift, and he treats it as such in the music. This shift occurs between bars 39 and 40, where the key area $\mathrm{C}$ must be transformed to $\mathrm{Db}$. To emphasize the large-scale structural key shift, this operation is predicated by a complete quarter rest in all parts. One might be 
tempted to construe this "record scratch" moment as a direct modulation to Db with no intermediary steps. However, Hindemith plants a modulatory seed within the prior phrase: the jarring dotted eighth-sixteenth rhythm that interrupts the trombone's attempt to resume the Theme 2 material in bars 38 and 39 leads into the full adoption of the dotted eighth-sixteenth rhythm in the Db key area at bar 40. This shift is shown below in Example 3.4.1.

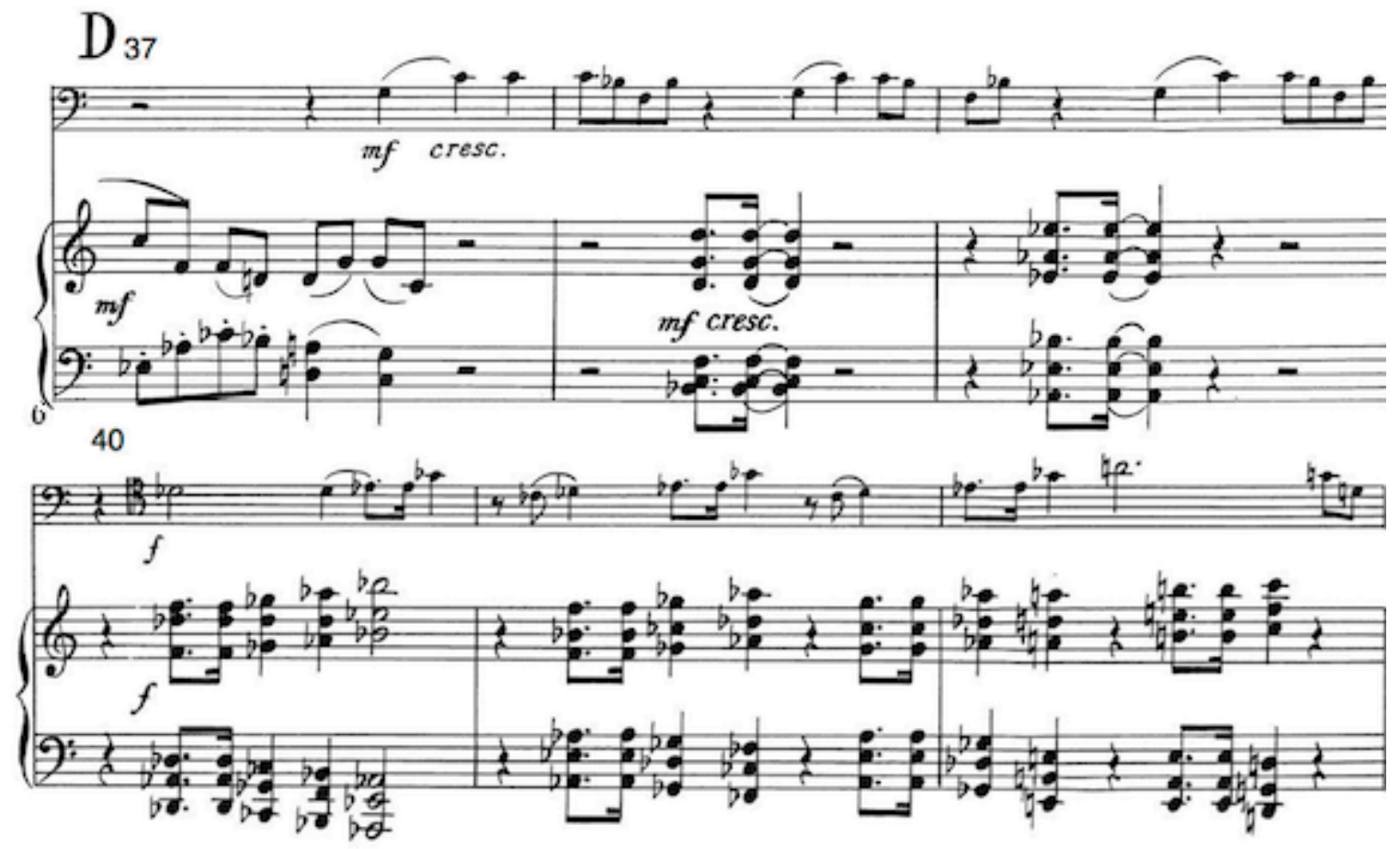

Example 3.4.1 Sonata for Trombone and Piano, mm. 37-42

A closer examination of these dotted figures reveals the underlying bass structure of $(-2,-7)$, a final culmination of the stepwise descent from the local F\# harmony present since bar 29. This shift is reminiscent of the ITD found within the first transition between F and C, which utilized a similar "step-leap" formula to arrive at a new key. This is the second most common of all of Hindemith's shifts, the 
first being the simple "falling tone" or (-1) descent. To reiterate my findings from Chapter 2, stepwise motion is important; half-step motion even more so. Stepwise motion often then leads to a leap motion within these motivic catalysts, as described in the previous examples. Highlighting the tension within the phrase is Hindemith's self-interruption of Theme 2, which is never completed and abandoned completely upon the mantling of the new key area.

Through Hindemith's sketches shown in Figure 3.1, Hindemith is shown to consider this tonal area structurally significant, yet it only lasts nine bars. Perhaps more telling about the level of importance is the way this phrase cadences, with a tertian harmony built on Db major, shown in Example 3.5. 

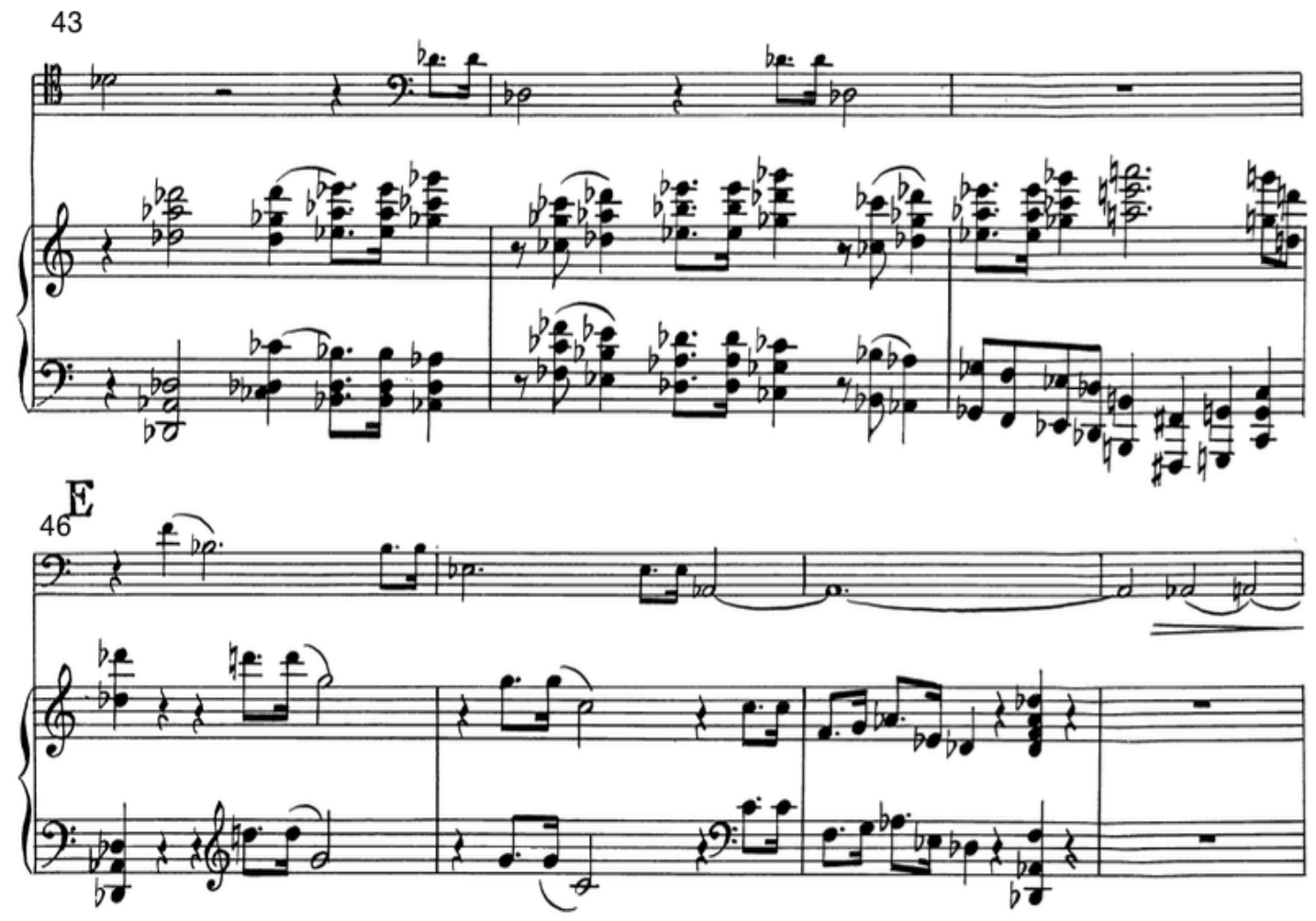

50

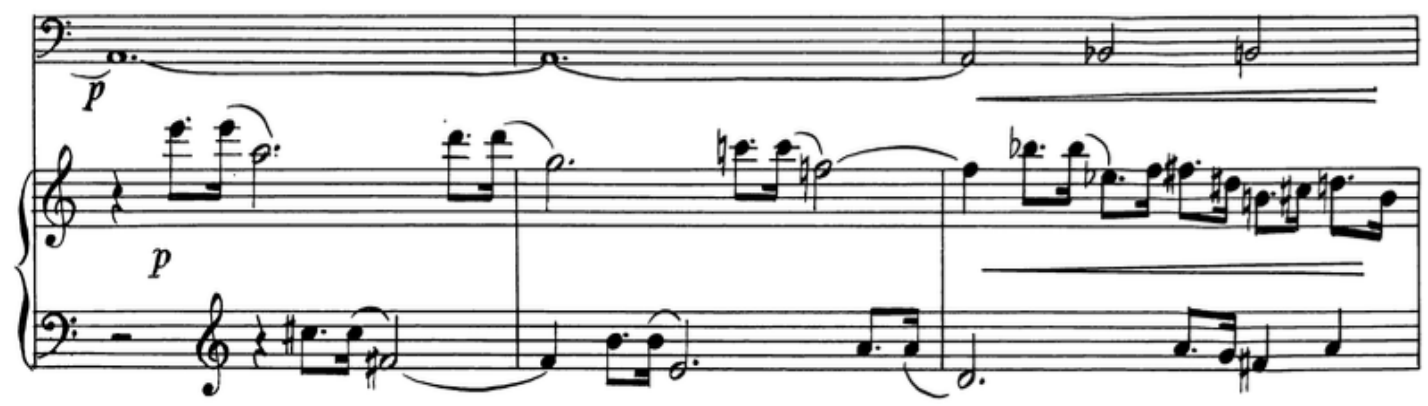

Example 3.5 Sonata for Trombone and Piano, mm. 43-52

Indeed, even the approach of the cadence is structurally significant and leads credence to a phrasal completion, with doubled-octave dotted-eighth/sixteenth motion leading from $\mathrm{Ab} / \mathrm{Eb}$ to $\mathrm{Db}$, a skeletal $\mathrm{V}$-I and perhaps one of the closest approximations in Hindemith's music to the traditional dominant-tonic hierarchism. 
In short, although the length of the section does not entail much structural significance, the cadence implies otherwise.

Another theory on the structural significance of this section lies within the half-step relationship. This section, occurring after a section that could be construed as the dominant, is the result of large-scale half-step motion between key areas. It mirrors the antecedent/consequent relationships of the basic phrasal period and the V-I relationship. Even though the half step here is a navigation of root-to-root of two key areas instead of leading tone-to-tonic, Hindemith viewed it significant enough to grace with a rare complete tertian harmony, in Db major.

The next transitional areas are on a more local, less structurally fundamental level, represented by unstemmed note heads in Hindemith's sketch. The music transitions from $\mathrm{Db}$ to $\mathrm{A}$ after 9 bars, and is again predicated by a textural shift. Highlighting the prominent rhythmic structure of dotted eighth-sixteenth, Hindemith negotiates through a series of perfect fifths before arriving and cadencing on a Db major triad, as described above. The trombone here acts reactively instead of actively; through bars 46 and 47, the call/response gestures between the trombone and piano culminate in the trombone leaving the melodic material completely and instead acting as a sort of pedal point in bar 48. The trombone then executes a half-step ascent, initiating a motivic succession of dotted eighth-sixteenth call/response between piano RH and piano LH occupying pitches that fit in the key area. However, bar 52 is marked by another half-step rise mirroring the one in bar 49. Instead of retaining the pedal point B, Hindemith 
utilizes the double half-step ascent as a launching point, ultimately $(+1,+1,+5)$, into a new key area of $\mathrm{E}$.

The tonal arrivals within these two new key areas (A and E) are instigated not by descent, but by ascent. Hindemith also construes these key areas in his notes as less structurally significant than the preceding and following key areas. This suggests that the presence of ascending motivic catalysts as opposed to descending motivic catalysts creates a cadence/transition structure that is fundamentally weaker and holding less structural weight than the other key area sections which are delineated by descending motivic catalysts.

The following transition, into the key area of Eb, occurs in bar 60, shown in Example 3.6 below. A resurgence of Theme 2 within the trombone (now transposed to $\mathrm{G}$ ) precedes the transition, and the sonic energy is carried back to the piano line, which undergoes a descending intervallic pattern before performing a quasicadence in $\mathrm{G}^{53}$ in bar 60 . The trombone again takes tonal charge, with an intervallic gesture of $(-2,+5)$. Again, the presence of ascending motivic catalysts leads to a key area denoted by Hindemith that is less structurally significant than the surrounding areas. However, as this motivic catalyst contains a mixture of both ascending and descending elements, it is perhaps fitting that Hindemith gave this section more structural significance than the preceding sections in A and E, which only contained rising MCs.

53 This is an example of Hindemith's use of hierarchical key areas; although it is not given in the key area graph of this movement, the cadential confluence suggests a local key area of G. 

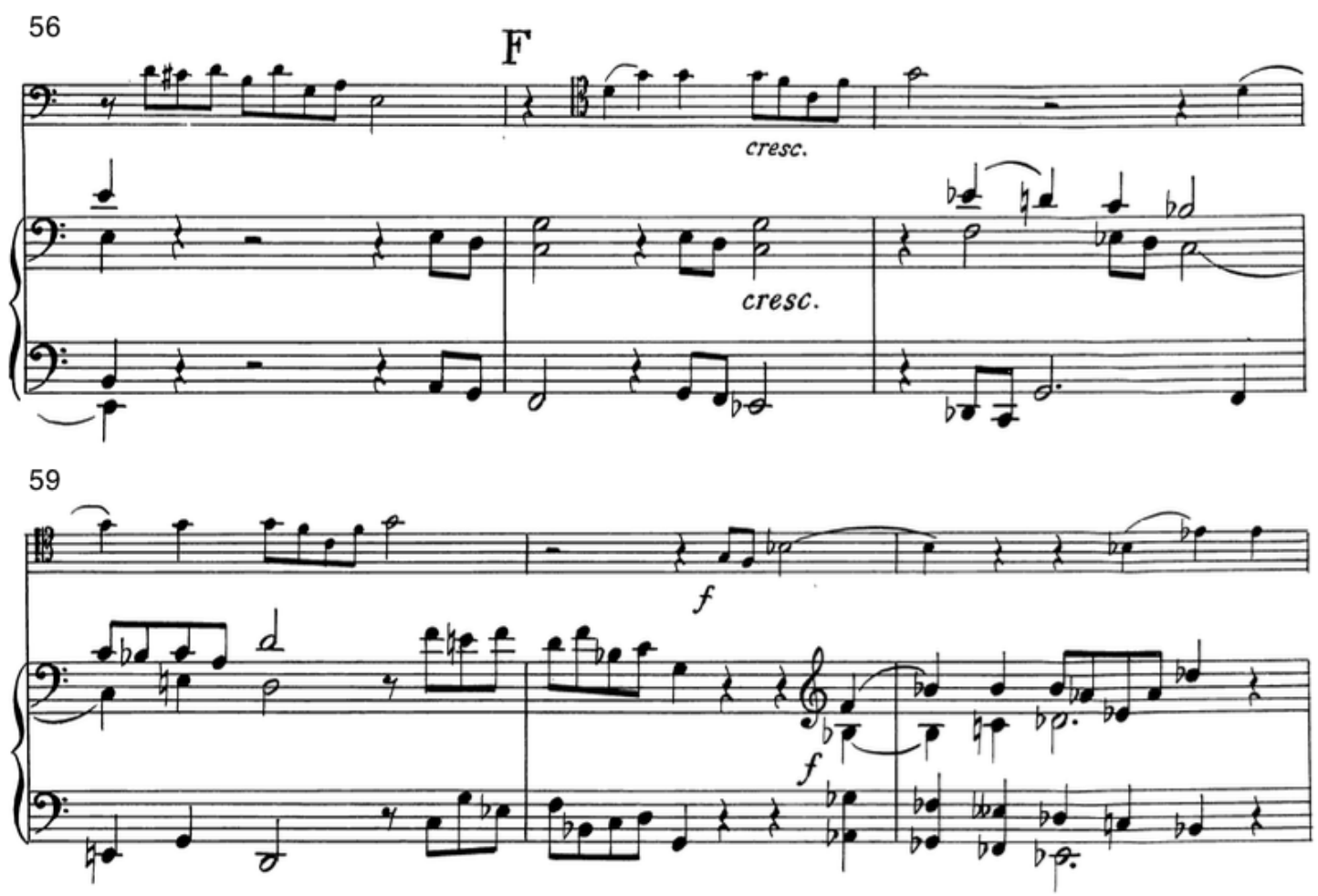

Example 3.6 Sonata for Trombone and Piano, mm. 56-61

The following key area of D occurs via direct modulation, as a result of a halfstep transformation of the Theme 2 motive in bar 64 . The non-catalytic motive $(-2,-$ $2,-1)$ is still present, but rather than the final $(-1)$ acting as falling tone that moves to scale degree 1 , it acts as a grounding anchor into what might be considered scale degree 5 , A. This instability of a pedal-point on scale degree 5 , functioning much as in the prior key area, leads to a quick resolution and the music shifts downward again into the key area of $\mathrm{Db}$. This motion echoes the prior iteration of this key area through a similar grounded-fifth harmonic context. This motion is shown below in Example 3.7. 


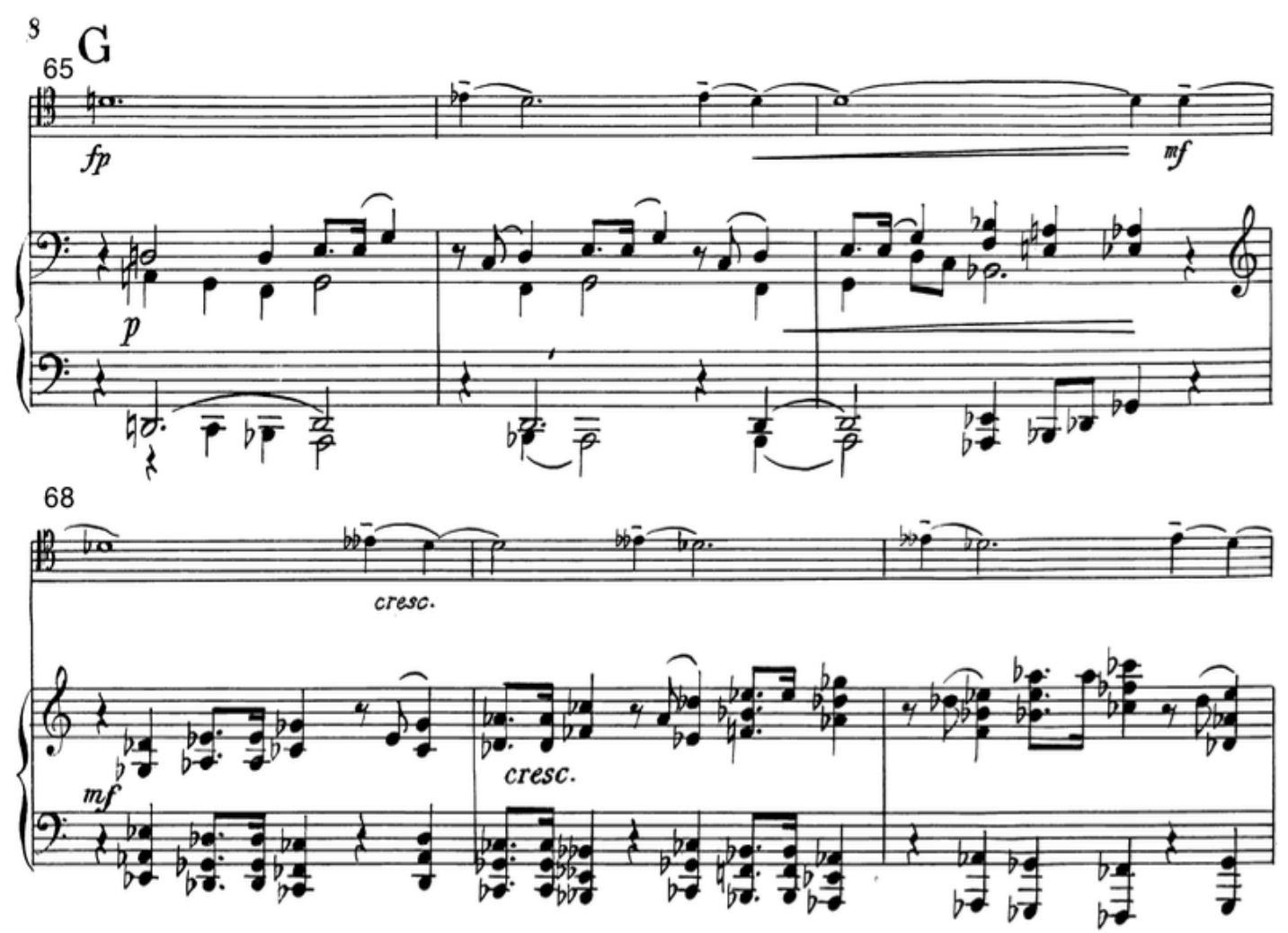

Example 3.7 Sonata for Trombone and Piano, mm. 65-70

The following section in Db, according to Hindemith's notes, is considered another lower-level key area and only lasts four measures, mm. 68-71. Notable is the resumption of the characteristic dotted eighth-sixteenth rhythm, which acts as a precursor to the next section where Theme 1 is recapitulated. This section is arrived by the motivic catalyst in measure 71 , which acts as a continuation of the preceding section's bass motion: the figure $(-2,-2),(-2,-2)$ in mm. 70-71 transforms into a $(-1$, $-2,-1)$ motive, with the final (-1) heralding the descent from the tonal area of $\mathrm{Db}$ into $\mathrm{C}$, the recapitulation. This is the final instance in the work of the falling tone halfstep descent, which acts as a tonal anchor and situates the piece in the tonal area of $\mathrm{C}$ until the end of the movement. 
The last few bars, from mm. 82-84, are indicative of a tonal breakdown and contains aspects of irresolution; the final movement in the trombone from $\mathrm{Ab}$ to $\mathrm{A}$ and the low bass chord of stacked thirds in inversion (Eb, G, B, D, F) does not provide a strong resolution, especially when compared to distinct major tonalities found earlier in the movement. The trombone slides into the high $\mathrm{A}$ as an anticipation of the next movement, which contains a global key area wholly in A, according to Hindemith's notes. These sections and movements, while separate musical entities, often function in conjunction with other movements within the greater sonata as a whole. The first movement of the trombone sonata, then, is not self-contained; it requires additional tonal context for a global resolution that is provided in the following movements.

\section{Analysis II: Sonata for Trumpet and Piano (1939)}

As a continuation of the issues procured from the trombone sonata, the first movement of Hindemith's 1939 Sonata for Trumpet and Piano likewise displays some features that bear investigating. As I have given an in-depth examination and classification of motivic catalysts in the trombone sonata, I will only examine a few instances of the phenomenon within the trumpet sonata while providing some more pertinent observations. . To aid in understanding Hindemith's tonal scheme in this movement, Figure 3.3 displays a graph similar to that found in Figure 3.2.54

\footnotetext{
${ }^{54}$ Note that this is my interpretation of Hindemith's key areas and is not reproduced
} from his sketchbook, unlike the trombone sonata graph. 


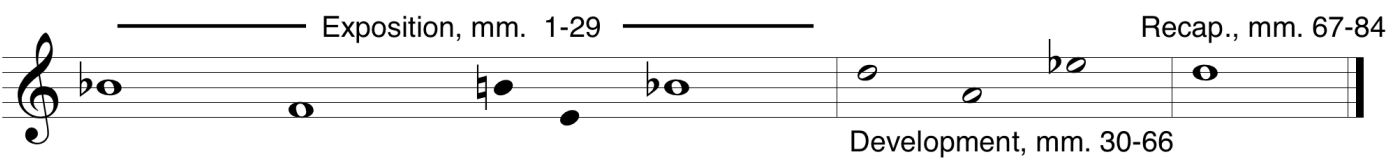

Figure 3.3 Sonata for Trumpet and Piano key area interpretation and formal diagram

As evidenced in the above Figure 3.3, the overarching structure of sonata form is present here; as in the trombone sonata, the recapitulation is uncharacteristically short and similarly does not conform to the expected tonal plan, with a final cadence instead on the mediant, D.

Although large-scale structural transitions by Hindemith occur mostly in the lowest voices in the texture, his melodic writing mimics some of these ideas at a more local level, where the melody can inform harmonic implications that would otherwise be provided by the bass. Ultimately, this strategy is a shift between musical spaces; a texture thought at first listen to be a secondary texture emerges and takes a primary role. Within primary space, Hindemith sometimes employs the same catalytic phenomena in the trumpet sonata that would inhabit a secondary space in the trombone sonata. In short, Hindemith sometimes makes the inner-voice phenomena of motivic catalyst more extrinsic by presenting them in the primary melody voice. This strategy can also be observed to a certain extent within the tuba sonata.

The figure below shows the first four bars of the trumpet part in its original transposed $\mathrm{Bb}$. The initial trumpet line in this movement consists of a two-bar antecedent figure that is fanfare-like, consisting of an expansive range and a quick 
dotted-eighth-sixteenth figure, a favorite of Hindemith. The first intervals navigated are the ascending perfect fourth and ascending major second.

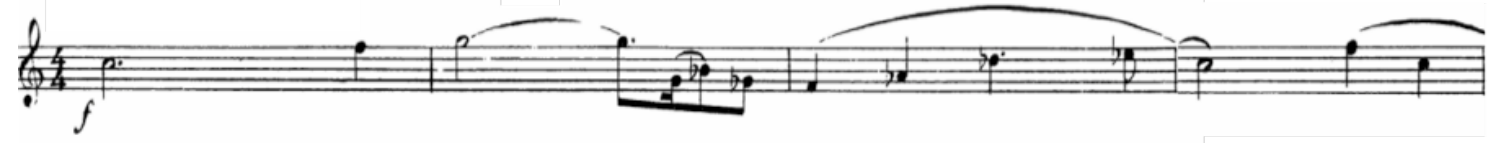

Example 3.8 Sonata for Trumpet and Piano, trumpet part, mm. 1-4

This motion ends with an abrupt registral shift and a lead-in to the next phrase, starting the consequent phrase on a written $\mathrm{F}$, which ascends in an arpeggiation of a first-inversion $\mathrm{Db}$ major triad. One can then view the antecedent phrase as more resounding, with use of perfect intervals, and an anticipatory lead-in toward a more triadic phrase ending. The phrase markings suggest the triadic motion is legato-an interphrasal style shift, which is apparent in the harmonic motion as well. Note that at the mensural onsets, the chord quality is open or stacked fifths in the antecedent phrase, and triadic in the consequent phrase.

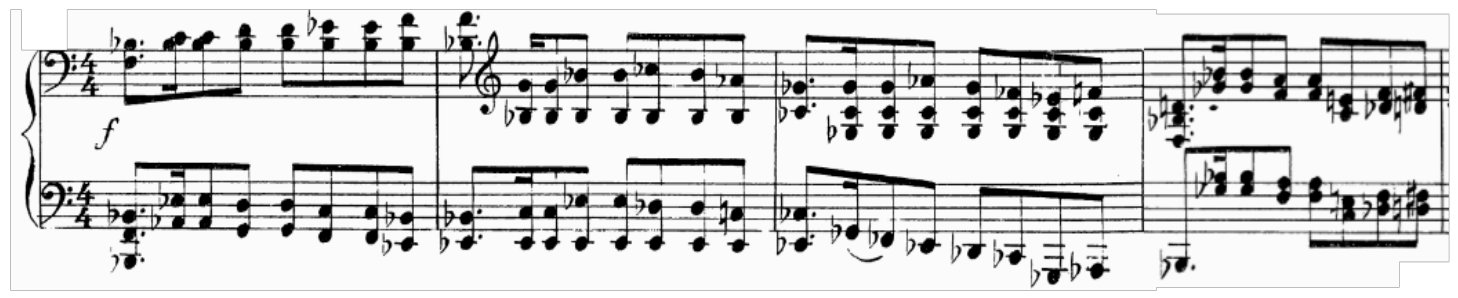

Example 3.9 Sonata for Trumpet and Piano, piano part, mm. 1-4

In Example 3.9, the melody acts as the motivic catalyst, much as is evident in the tuba sonata. Compared to the robust fanfare figure, the unexpected descent $(-4,-$ 
1) contains the characteristic half-step motion that is also present in many cases in the trombone sonata as a motivic catalyst and falling tone, drawing the sonic energy downward and typically heralding a key area shift. Although the trumpet outlines inter-chordal voices instead of the root of the chord, it is a striking descent and one that brings about a stylistic shift in the melody, reinforced by mensural-onset triadic attacks.

A formal analysis of the first movement of the trumpet sonata reveals the expected display of sonata form. This formal structure is denoted by the presence of a small-scale AABB phrasing within the exposition, mirroring the thematic sections, where the solo instrument provides the first theme that is then repeated nearly verbatim by the piano while the solo instrument rests. The lack of piano introduction or similar "key supplementations" throughout the introductions of these sonatas is indicative of the direct, immediate harmonic language that Hindemith employs.

The key areas of the trumpet sonata are not revealed in Neumeyer's reproduction of Hindemith's notes, but they can be discerned with a careful analytical eye. Much like in the trombone sonata, the primary theme appears in the main tonal area of the work, $\mathrm{Bb}$, and the second theme appears in the dominant, $\mathrm{F}$. The approach from $\mathrm{Bb}$ to $\mathrm{F}$ is preceded by the motivic catalyst in bar $8,(-7,-1)$, again hashing the falling tone from $\mathrm{Gb}$ to the new tonal center of $\mathrm{F}$, shown in Example 3.10. 


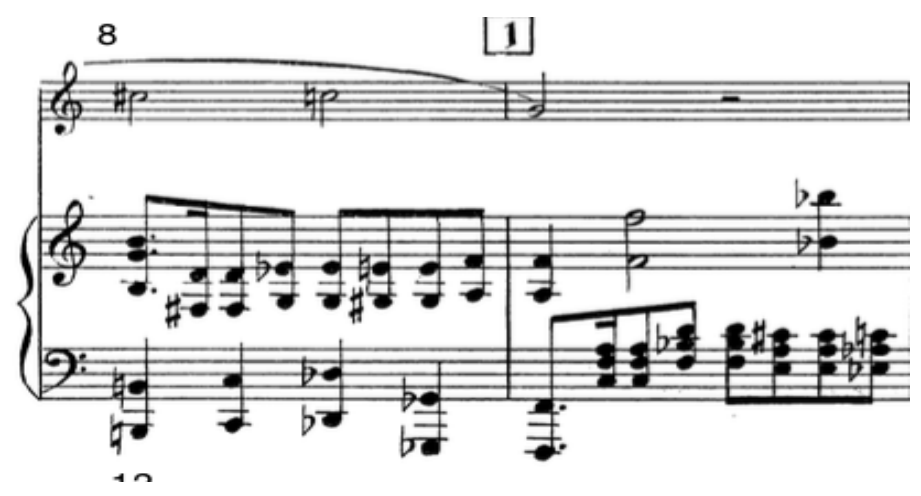

Example 3.10 Sonata for Trumpet and Piano, mm. 8-9

Continuing from $\mathrm{F}$, the music makes a jarring shift into the key area a tritone away in bars 15-16. This shift is achieved by a descent in the trumpet line and a rising motivic catalyst in the piano, $(+3,+2)$, which results in an intermediary major triad in B, setting up the piano for a return to the main thematic material transposed up a half-step from its original iteration, shown in Example 3.11. The ramifications of such rising motivic catalysts will be further explored in a subsequent chapter. 


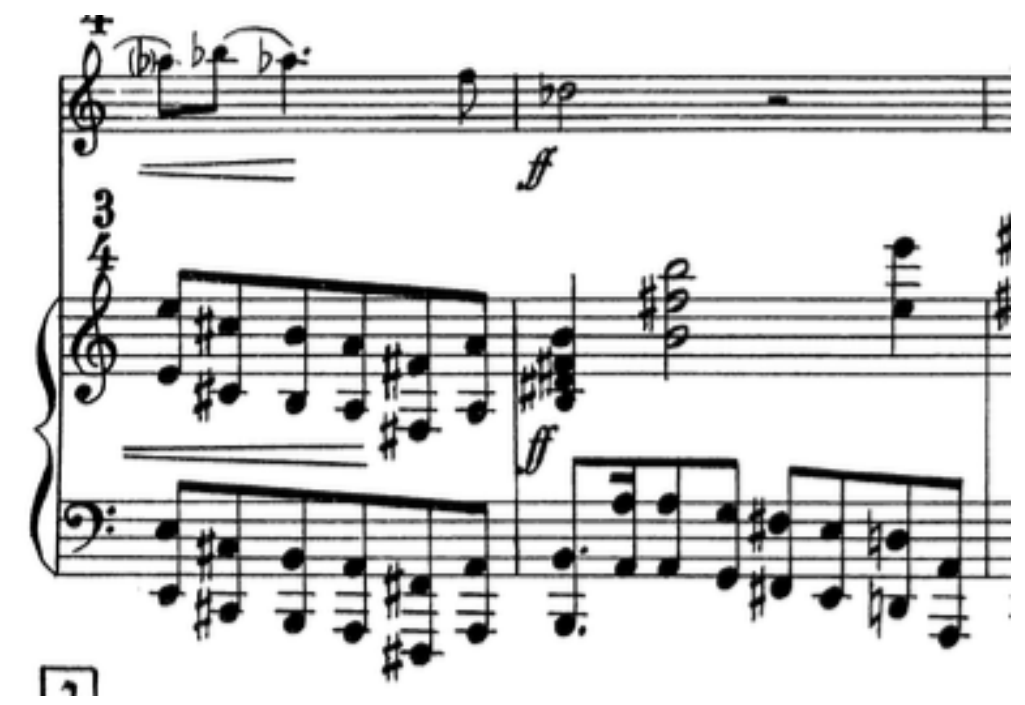

Example 3.11 Sonata for Trumpet and Piano, mm. 15-16

The next key area movement towards $\mathrm{E}$ in bar 19 is arrived at via $(-5,-1)$ motion. The initiating tone of the motivic catalyst is $\mathrm{Bb}$, as the tonality of the key area begins to break down from B; the final half-step descent towards $\mathrm{E}$ is a final action of this motion. To transition away from this section, the bass initiates another $(-5,-1)$ gesture that leads a tritone away, back to the initial area of $\mathrm{Bb}$, shown in Example 3.12.

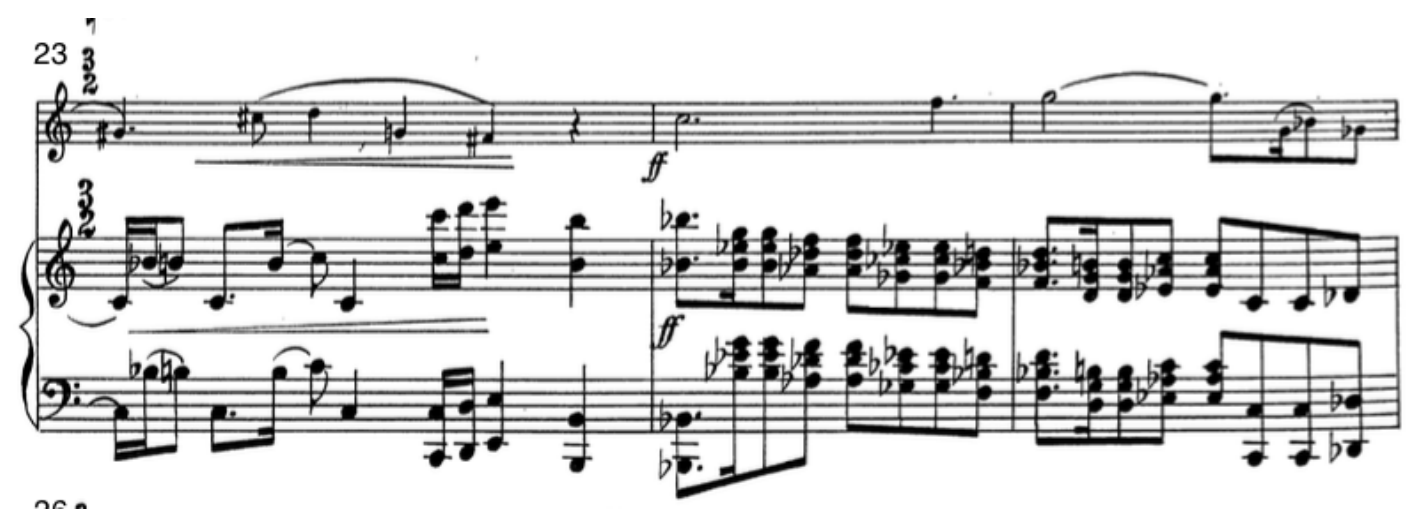

Example 3.12 Sonata for Trumpet and Piano, mm. 23-25 
With this initial area also comes a repetition of Theme 1, which is truncated at the $3 / 2$ bar and precedes a transitional pointillistic section of triplet motion that leads into a broader transition of polyphonic, octave-doubled piano material. The key area of this section, beginning in C\# (occasionally written enharmonically as $\mathrm{Db}$ ) undergoes tonal shift that is very chromatic and sudden; I would classify this section as one which does not contain a discernible motivic-catalytic structure of tonal forthcoming, although it ultimately does reside within the C\# area with chromatic alterations.

The following melodic and harmonic content of the trumpet sonata continues in a similar vein, and I will choose not to hash out each individual motivic catalyst and key area transition due to a similar repetition of material. The primary feature in this section, again, is the use of primarily descending motivic catalysts to propel the music into diverse, hierarchically significant tonal sections. To finish the movement, the primary theme resurges in the trumpet at the marking "Breit" in bar 67 , serving as a recapitulation and ultimately brings about a final cadence in the mediant, D.

\section{Analysis III: Sonata for Tuba and Piano (1955)}

The tuba sonata, written over a decade later than the other works analyzed in this study, may be interpreted as either a maturation of Hindemith's style ${ }^{55}$ or as a complete departure from it. ${ }^{56}$ From a structural perspective, the tuba sonata is perhaps the most atypical of all the sonatas Hindemith composed for brass and

55 Neumeyer, The Music of Paul Hindemith, 30-34.

56 Payne, 198-200. 
piano, recalling elements from his earlier neue Sachlichkeit style and heretofore-

unseen serialist elements. On the tuba sonata, Dorothy Payne writes:

The first movement may be classified as a type of sonata form. The ten-measure principal theme, relegated exclusively to the tuba, is heard in conjunction with a secondary motive found in the piano part. The second theme consists of two brief, motivic ideas, each two measures in length, the second of which is re-shaped into the four-bar subject of the fugato which comprises the entire development section. The coda is also based on the second half of the B theme, and is likewise imitative. ${ }^{57}$

The most notable feature of this sonata is the treatment of the solo tuba part as essentially secondary to the piano part. While the tuba takes on some of the broader melodic load, the piano bears much of the responsibility throughout for shaping interesting melodic lines and providing tonal instability and repose. The tuba, on the other hand, can be seen as a more or less melodic bass, and consequently is the purveyor of MCs and ITD throughout the setting. Though the other brass sonatas have instances of this phenomenon, the tuba part here is unique as it consistently produces lower notes than the piano and thus suiting the role of ITD progenitor. This is perhaps important to note, as it shows that this device has more preponderance in regards to pitch level than texture or contextuality.

Similarly to Figures 3.2 and 3.3, Figure 3.4 shows my interpretation of the key areas within the tuba sonata along with a formal diagram.

${ }^{57}$ Ibid, 26. 


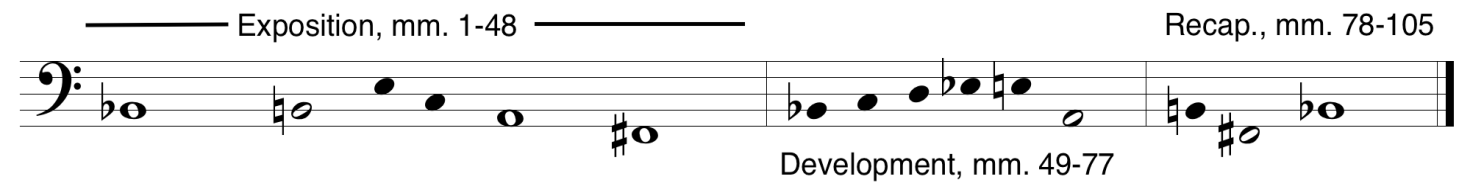

Figure 3.4 Sonata for Tuba and Piano key area interpretation and formal diagram

Key areas within the tuba sonata are not explicitly defined in Neumeyer's Hindemith notes, unlike with the trombone sonata, and the quasi-serialist nature of the piece alongside the fugato of the development leads to an unclear tonal hierarchy. Despite the hierarchy being unclear, the larger sections still display iterations of medium-scale transitional functions and must be analyzed further.

The overarching form of the tuba sonata follows the broad pattern of the other sonatas, with some departures. Shown in the formal graph, the development begins in earnest in the pick-up to bar 49 , and the recapitulation starts at bar 78 after a languid transition. This leaves some room for interpretive analysis. Departing from the stricter adherence to sonata form found in the trombone and trumpet sonata, the tuba sonata instead displays a number of shorter thematic ideas.

The primary theme of the tuba part is the expansive ninth-relation motive found in the beginning of the movement. This is accompanied by an increasingly dissonant triplet figure in the piano line, which eventually morphs into a new thematic idea. Instead of presenting clean themes with clear key relations, Hindemith smudges the edges of the auditory palette here and throughout the movement. The striking duality of the piano and the tuba is always present and typically at metric odds; when the tuba presents duple-related material, the piano 
will counter with triplet-related melodic material. The exposition ends in a cadence in F\# major, and is interrupted with the hectic developmental material after a brief pause.

The development pits the tuba and piano against each other in a more substantial way, each one attempting to gain a foothold in the evolving tonal landscape. The intense chromaticism here lends itself to a more motivic approach than a broad-brush designation of key area; Dorothy Payne's analysis reveals a similar lack of clarity regarding key area. The transition back into the recapitulation-here, transposed a half step higher than the beginning expositionis a play on the initial triplet piano figure. The ending codetta in Bb cadences with a major triad, making this the first sonata examined in this document that could be considered self-contained within a single key area; that is, it begins and ends in the same key area.

A more in-depth look at the key relationships in the first movement of the tuba sonata will reveal a departure from the intermediate-level demarcators found in the previous sonatas examined. Below in Example 3.13 are the opening 11 bars of the tuba and piano. 

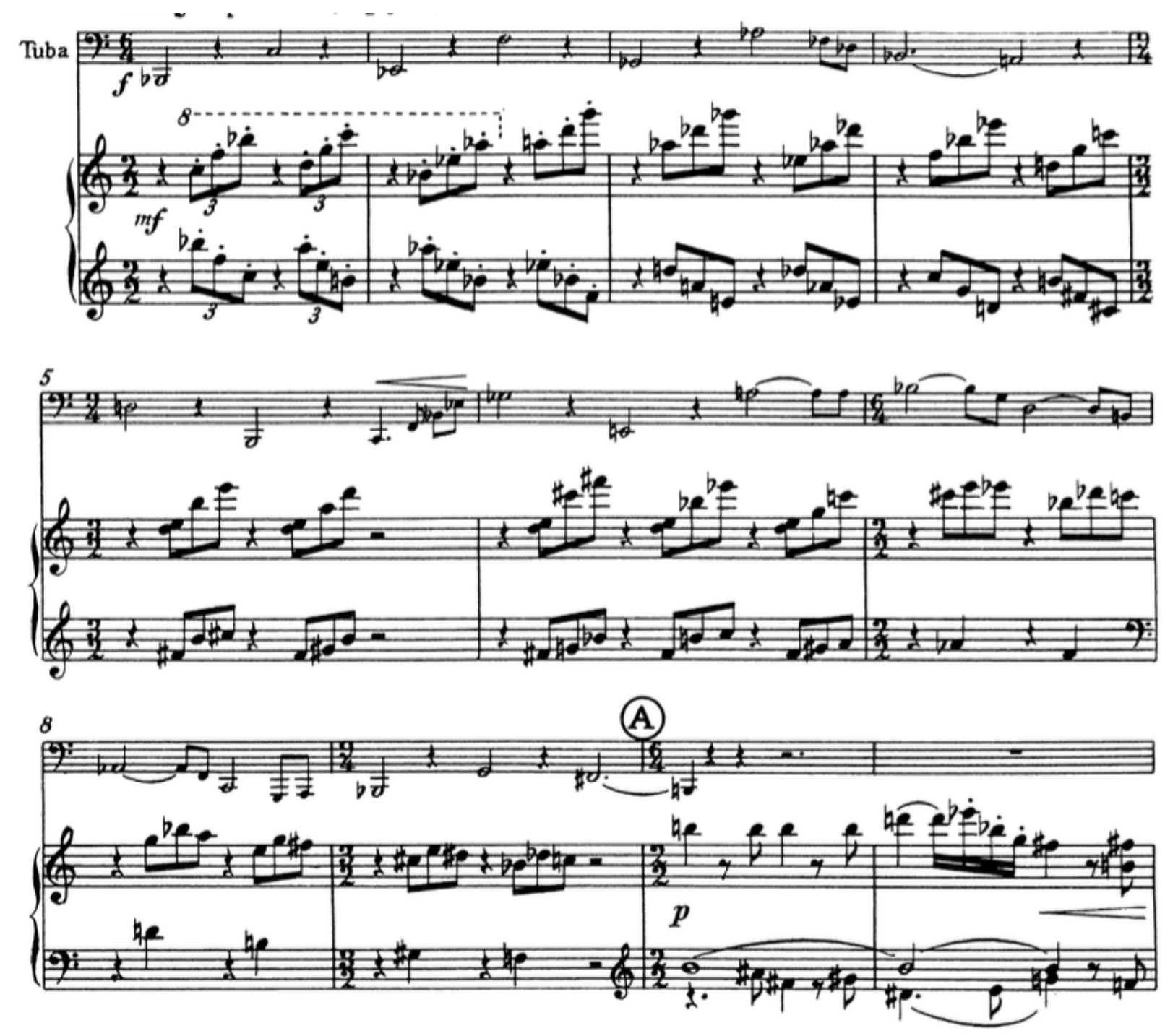

Example 3.13 Sonata for Tuba and Piano, mm.1-11

Contextual clues reveal an initial key area of Bb, shown in the graph in Fig.

3.4. Latching onto structural figures of broader senses of pulse will aid our interpretation of key areas-that is, observing what pitches are given significance at the onset of downbeats and phrases. Much as is commonplace in eighteenth-century common-practice styles, harmonic change accelerates as the music nears cadential areas. 
At a surface level, we can trace the opening tuba line as a compound melody that highlights two second-inversion minor triads a ninth apart. The half-step descent in the fourth bar ends up being a structurally significant interval that colors Hindemith's composition of the entire piece. The large, disjunct leaps in the tuba line point toward a less melodious entity and a more accompanimental feature. I contend that the solo tuba voice in this music assumes the function of both presenting a referentially-consistent line in accordance with Hindemith's theories on melodic construction ${ }^{58}$ and also as an ornamented conveyor of the motivic catalyst that defines the piece; namely, the catalyst $(-1,-7)$ that is seen as a structural delineator in this section.

We may take mm. 4-5 and mm. 9-10 above as examples of the motivic catalyst principle in action. As evidenced in the other sonatas, Hindemith uses the lowest voice-typically, the left hand of the piano—as the conveyor of the motivic catalyst. In the tuba sonata, exceptions must be made, as although the tuba is the solo voice and the main timbral feature of the work, it is also the lowest voice in a three-voice texture. It therefore takes upon itself the function of motivic impetus, a sort of trichord springboard that launches the music into a new tonal area.

As previously mentioned, the motivic catalyst of $(-1,+7)$ is revealed in the solo tuba line between m. 4 and m. 5, where the local key area of Bb shifts to D. Along with this movement of a third, the piano line begins to become more dissonant, exemplified by the offbeat trichords that supersede the offbeat dyads. This section is less dense than the opening bars in a few respects, but is mostly

${ }^{58}$ More on Hindemith's theories on melodic constructs can be found in Craft of Musical Composition, 183. 
stable, and does not contain a motivic catalyst. As it is not a transitional section, this section "rests" upon the given D-type tonality until m. 9, where we see the tuba provide yet another motivic catalyst of $(-1,-7)$. In short, some of the functional aspects of motivic catalysts can be found at differing levels of structure. Although this entire opening passage is ostensibly in the key area of $\mathrm{Bb}$, the localizations of $\mathrm{D}$ key area makes for a more harmonically clear reading of the tonal map.

The first major tonal shift from $\mathrm{Bb}$ to $\mathrm{B}$ is predicated by the $(-1,-7)$ catalyst in the tuba part at bar 9, as I have described. Most of the catalysts in this example do occur in the tuba part, which is in contrast to the previous examples studied. The shift into bar 22 is reminiscent of the prior $(-1,-7)$ catalyst found within the $\mathrm{Bb}$ section, although it lacks the descending fifth component. Instead, this might be considered simply a $(-3,-1)$ catalyst, as the impetus into the new key is borne by a descending triadic pattern that holds no real structural significance until the (-1), the falling tone. The catalyst brings about a descent to the key area of A, which lasts a scant two bars before being superseded by the repetition of Theme 1 in C, whole step higher at bar 24. This relationship from A to C bears no falling tone, instead coming on as a result of a $(-2,-5)$ shift. It should be noted that the motion of $(-5)$ or $(-7)$ is still a structurally strong one to the ear, perhaps with not as much gravity or pull as a half-step relation, but still a palpable one. This relationship is shown below in Example 3.14. 


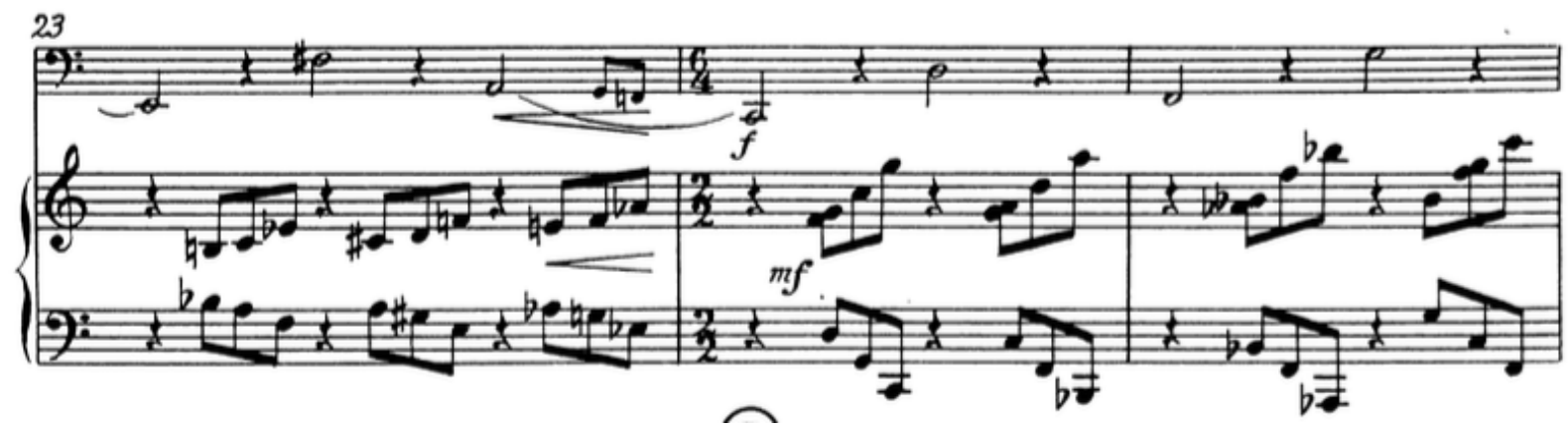

Example 3.14, Sonata for Tuba and Piano, mm. 23-25

From the key area of $C$, Hindemith uses the ubiquitous $(-2,-1)$ motion to return to A in measure 28, shown in Example 3.15.

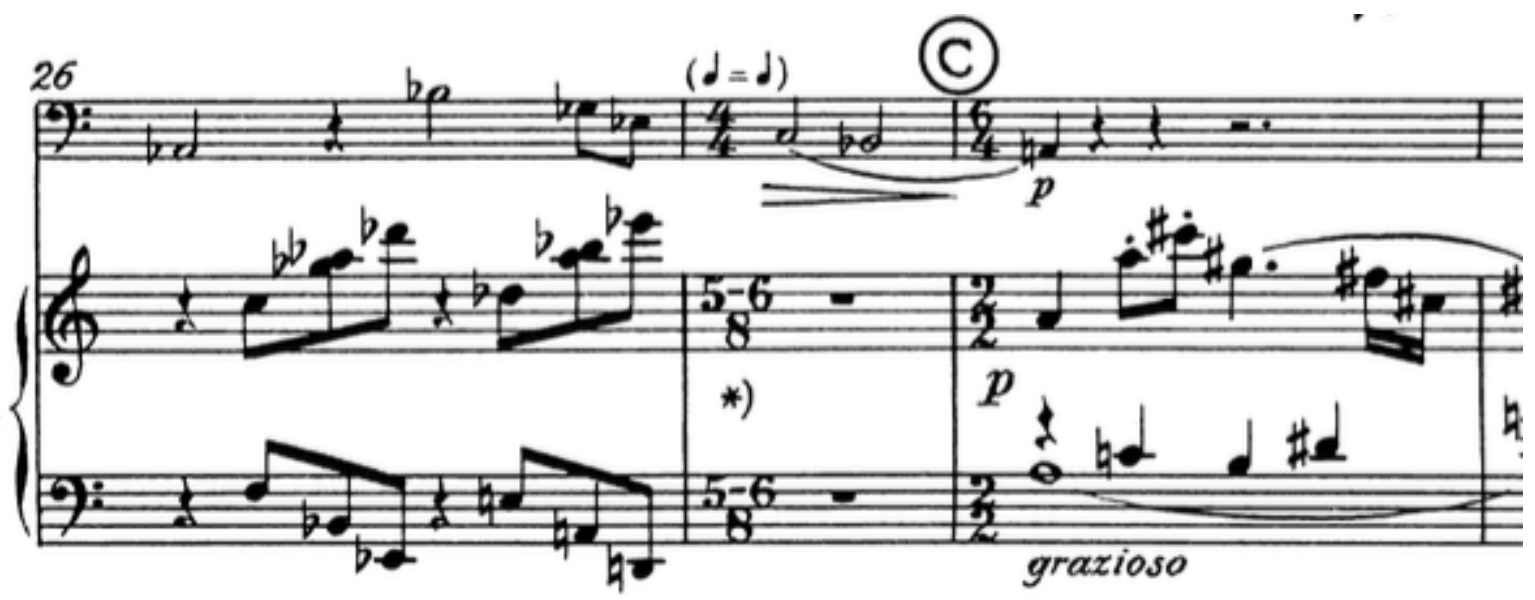

Example 3.15 Sonata for Tuba and Piano, mm. 26-28

This signature catalyst could indicate a higher level of structural significance, and it does, in fact, herald the secondary theme, which is mostly a piano-led melodic excursion with the tuba providing some rhythmic counterpoint interjections. This minor third descent, which marked the prior sectional boundary, returns as the tuba 
provides yet another $(-2,-1)$ catalyst to $\mathrm{F} \#$ in bar 42, displayed in Example 3.16 below. Structural weight is again bestowed to that which follows $(-2,-1)$ by the presence of an F\# major triad at the end of the section at bar 47, a rare auditory phenomenon in the quartal and quintal harmonies that Hindemith typically allows for.

$=$

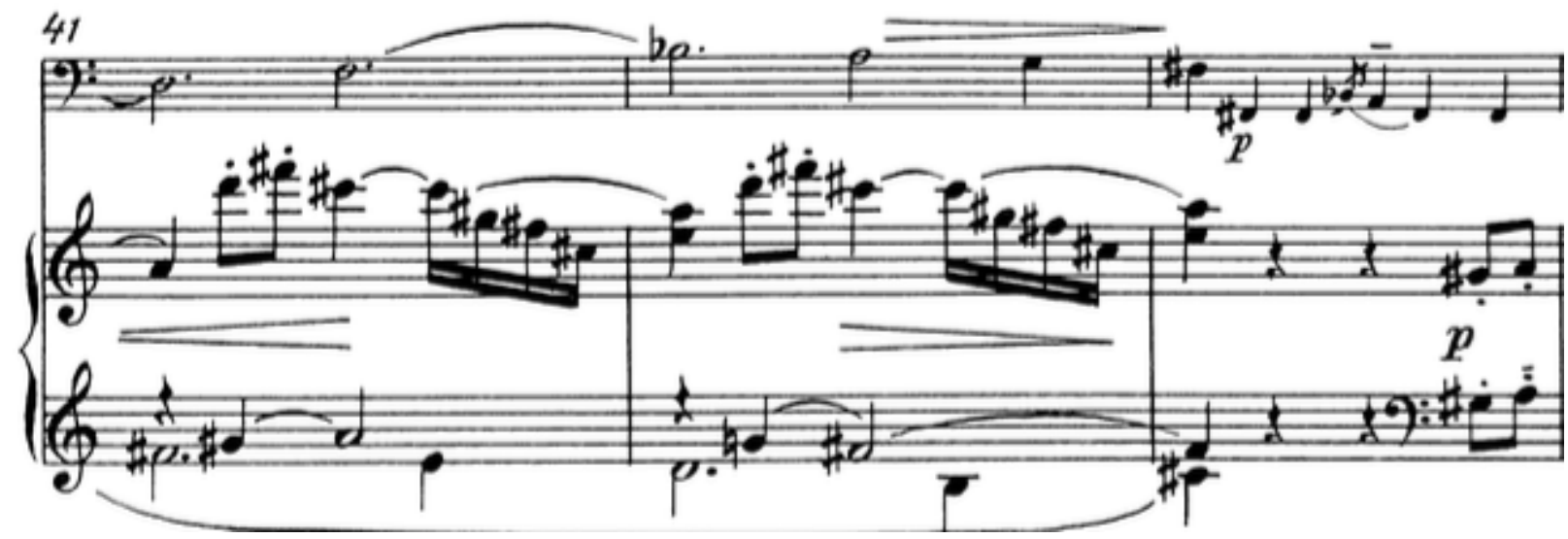

Example 3.16 Sonata for Tuba and Piano, mm. 41-43

The development section is difficult to categorize into tonal areas. It is rife with counterpoint, and provides key areas that are distantly related and seem to come about by result of direct modulation. The falling tone is present throughout, though, and might be understood as Hindemith's hallmark on this development section, where it is not used as a melodic falling tone; the half-step descent occurs near the end of the dissonant, rhythmic development counterpoint and can be understood as an end-marker on a lower structural level that is not governed by absolute key areas. 
To return from the development, Hindemith employs a four-bar transition at bar 74 marked poco largamente. This formal transition ${ }^{59}$ is comprised of descending stepwise figures that either purvey or prohibit the half-step descent figure in the tuba. The piano is marked by an inversion of the initial Theme 1 line, employing descending ninths. The final half-step motion provides a $(-2,-2,-1)$ catalyst in $C$ to decline towards the key area to B at bar 78. After a few resultant bars of chromatic descent, $\mathrm{Bb}$ emerges as the final key area, although it is not arrived by a half-step catalyst, and ultimately coalesces within a major sonority after a brief codetta.

These studies demonstrate that the pertinent sectional elements in the trumpet and trombone sonata are again present here. Namely, this study has shown that half-step motion is structurally significant; the falling tone leads toward key areas that are more prominent than others. Only once, in the codetta, does Hindemith not present a significant musical section after the presence of these halfstep indicators. Structural significance, again, is defined by factors such as key area length, the presence of fundamental harmonies such as triads, and the presence of primary or secondary thematic material.

Within the broader scope of these three works, a few observations on the behavior of ITD and the related phenomenon of MC emerge:

1. The initiating tone of the motivic catalyst must be closely related to the antecedent key area.

2. The final tone of the motivic catalyst must be a fundamental "pillar" of the consequent key area.

${ }^{59}$ N.B.: This formal transition should be differentiated from the transitional phenomena between key areas; while the two can overlap, it is not always the case. 
3. The number of pitches within the motivic catalyst must be more than one, as they are transitory and require a "from" and "to"; three is the most common, though longer lines do occur.

4. Motivic catalysts typically occur at the quarter note (or larger) rhythmic level, though they can be implied reductively in dense contrapuntal textures.

Such analysis and classification of mid-level function helps us better understand Hindemith's tonal style and pushes the possibility that Hindemith intended these primarily descending gestures to inform our listening. Moreover, the presence of these structures reflects largely on Hindemith's neoclassicism, and the inclusion of such structures as a facet of his neoclassicism helps to further categorize, analyze and understand how neoclassical structures operate. Combined with interpretations of Hindemith's tonality in Chapter 1, these analyses help fully inform our understanding of discrete interphrasal elements in Hindemith's work. This relates more to the material I will discuss in the following chapter, which delves into the neoclassical and pedagogical ramifications of Hindemith's sonatas and takes a closer look at elements of the horn sonata. 


\section{CHAPTER 4}

\section{HINDEMITH AND NEOCLASSICISM: THE HORN SONATA AND VARIABILITY OF TERMINAL STRUCTURE}

Thus far, my analyses have shown terminal cadential/transitional techniques in three of Hindemith's sonatas for brass. With a few exceptions, the cadential and transitional figures within these pieces embody the principle of descending stepwise gestures that signal a shift in key area. It should be understood that these figures only represent a small cross-section of Hindemith's work; as such, not every possible cadential/transitional technique is represented, and not all of Hindemith's works fits so neatly into the stepwise terminal descent paradigm. The first movement of the 1939 Sonata for Horn and Piano illustrates the variability of such terminal structures.

Consider Example 4.1 below, which shows a passage transitioning from the key area of $\mathrm{C \#} / \mathrm{Db}$ to $\mathrm{F} \# / \mathrm{Gb}$ at $\mathrm{m} .64$. Though the piano exhibits chromatic variance from m. 61 to m. 63, the solo horn in F remains firmly entrenched in the C\#/Db sonority until the bass terminal gesture at m. 64 . This results in the aforementioned key area shift along with a textural change as the piano picks up the horn theme. 


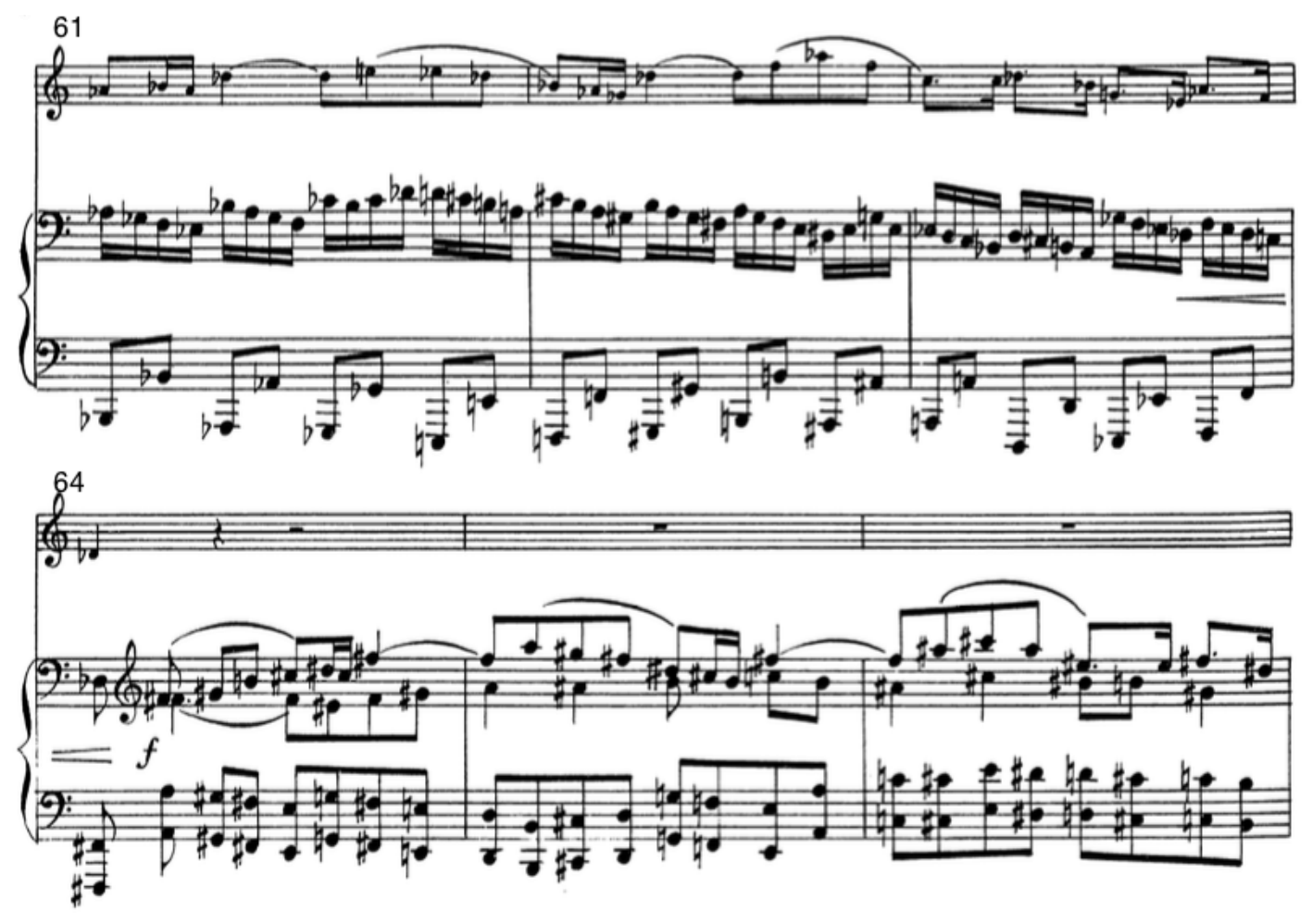

Example 4.1 Sonata for Horn and Piano, mm. 61-66

Example 4.2 also shows a tonal shift that exhibits terminal stepwise motion.

Here the shift from $\mathrm{D}$ to $\mathrm{F} \#$ generates from the terminal gesture in the bass at $\mathrm{m}$. 104. Again, a shift from a monophonic to denser polyphonic texture accompanies the tonal shift. 


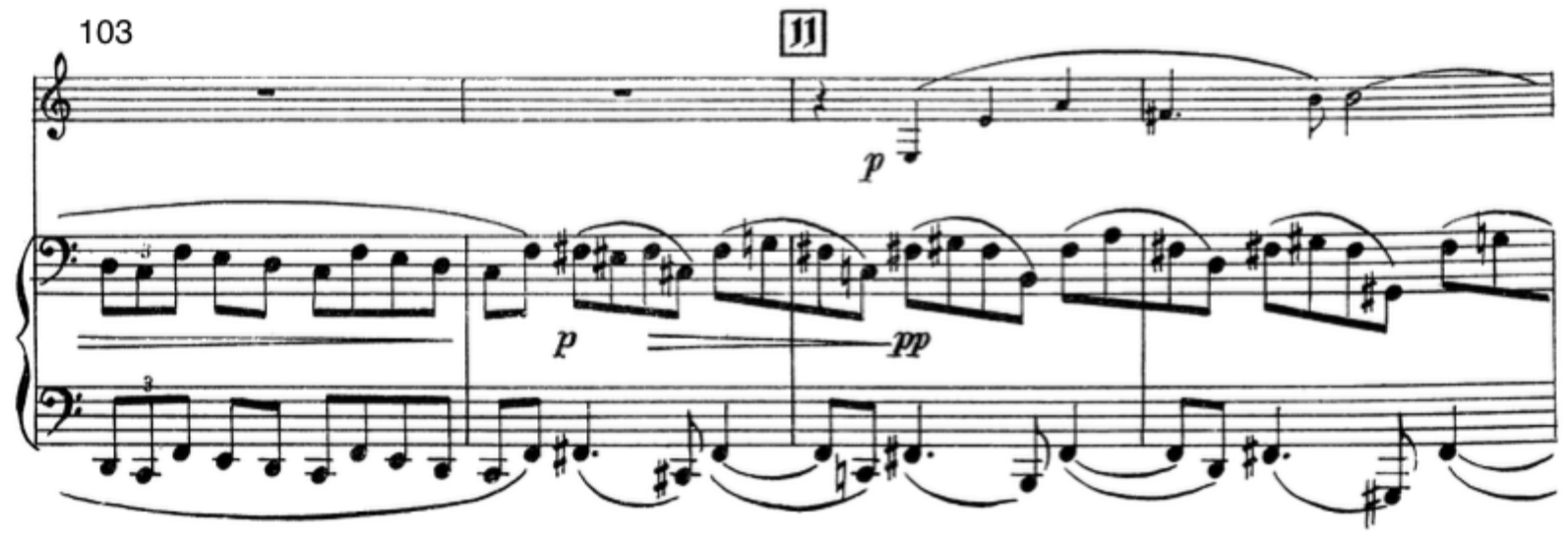

Example 4.2 Sonata for Horn and Piano, mm. 103-106

What are some of the preceding factors in these shifts, and how are they different from those previously examined? The key areas themselves can be deduced from a cursory analysis of the subsequent tonal areas and the existence of terminal transitional gestures, which are familiar to us now with our understanding of Hindemith's techniques. The puzzling (and fundamental) aspect at work here, then, is the primarily rising motion in terminal gestures as opposed to the previously seen descending motion. While this occurs in other works examined in this study, ${ }^{60}$ such occurrences are structurally and hierarchically less prominent, nearly incidental compared to the overall tonal design of those pieces. Within the horn sonata, this repetition lends a level of prominence to these rising gestures, casting them in a higher hierarchical light than those found in those works examined earlier in this document.

Other key areas of this piece, while not all exhibiting characteristics of stepwise ascent as shown in the above examples, display either a tendency towards ${ }^{60}$ Refer to previous analysis of Hindemith's Sonata for Trumpet and Piano and Sonata for Trombone and Piano. 
non-linear breaks in the accompanying line, or stepwise terminal descent that is not in an inner or lower voice. These factors show a definite break from the paradigms observable in the other brass works examined in Chapter 3. Although the cadential phenomena that can be reduced to motivic catalysts and their underlying functions - the half steps being more indicative of a stronger cadential pull, whole steps and leaps designating a weaker cadential pull—there are other, less common cadential and transitional methods in use.

To further understand Hindemith's methods, we must go further and look at not only the intervallic content being spanned within each terminal nexus, but also at the overarching form of the movement. The horn sonata does not fit neatly into the sonata-allegro form trope. There is instead a sense of long ternary form; vestiges of development and recapitulation exist in the formal framework that Hindemith provides, but these formal articulations are expanded and even warped. The "B" section, starting at $\mathrm{m} .55$, has aspects of development, but it is lengthy and demarcated by a double bar line and the stylistic indicator "Frisch."

Fragments of themes do resurface in the development, but there exist many thematic divergences from the Hepokoski and Darcy model. Such subordinate themes appear primarily in the development and are generally small, self-contained ideas. These subthematic gestures act as more passing ideas than as integral developmental seeds within the section. In short, the uncharacteristic formal structure here, while similar to sonata-allegro form, could be thought of as sonataallegro form stretched and pasted over a much longer template. The movement is replete with varied thematic articulations and a plethora of smaller, incidental 
thematic fragments that only tangentially relate to the main themes. Key area navigation is similar to that of other works, but elevates the ascending terminal gestures to a more prominent structural level and occasionally evades stepwise relationships entirely.

Indeed, perhaps the most important link within Hindemith's music of this period is the intimate relationship between form and function, and the horn sonata shows that form and function can coincide in various ways, pointing toward a more thoroughly neoclassical understanding of Hindemith. The evolution and development of cadential/transitional terminal gestures within his other works mirrors the evolution and development of formal issues within this movement. Moreover, this movement shows the variability of such terminal gestures; while the primary focus thus far has been on descending, stepwise terminal gestures, here Hindemith presents terminal gestures that are not necessarily descending and not necessarily stepwise, construed as hierarchically prominent due to factors such as repetition or an implied dominant $\rightarrow$ tonic relationship, aligning with Hindemith's conceptions of tonality. ${ }^{61}$

\section{Hindemith and the Neoclassical Puzzle}

This analysis suggests that Hindemith's works show both normative configurations and rare exceptions to this normativity. Reflecting on the classical tradition from which formal neoclassicism is extrapolated, one finds an abundance of cadential and transitional methods in the literature; there are many rich possibilities of cadential variation and their use varies on a practically phrase-to-

${ }^{61}$ More can be read about Hindemith's Series 1 and Series 2 as a means for composition and tonal architecture in Craft of Musical Composition. 
phrase level. Within classical works, although the perfect authentic cadence is the tonality-defining gesture, other cadence types are encountered enough that their varied usage within a given piece, depending on context, is stylistically appropriate. Within Hindemith's neoclassicism as evidenced by these sonatas, the PAC analogue is the (-1) motion, as it leads to the more tonally- and structurally-significant areas of the music. Other terminal motion, such as the ascending gestures, lead to areas of the music that are less significant. However, just as some composers might use a plagal cadence instead of the expected PAC, the horn sonata uses these ascending gestures to arrive at areas that are structurally prominent.

Transitions are varied as well, either through the formal sonata syntax espoused by Hepokoski, Darcy and Caplin, or through other methods by which composers evade or elide cadences and link formal sections. The usage of these terminal structures is largely dependent on harmonic and formal context, and varies from piece to piece and composer to composer. Mirroring this varied usage of cadence is Hindemith's adaptation of similar varied terminal structures: a neoclassical reimagining of cadential/transitional space.

The variation of such terminal structures, the shifting or disruption of terminal paradigms, strengthen and inform our knowledge of Hindemith's neoclassicism. Within the brass sonatas, the horn sonata can be understood not only as an outlier, but also as an indicator of the richness in variation that can be derived from the neoclassical interpretation of traditional structural formats. ${ }^{62}$

62 That transitional demarcators in the horn sonata do not follow the normative schemes observed in the other brass sonatas point toward a need for further research in this area that is outside the scope of this document. 
What does the variance found in the horn sonata tell us about Hindemith and neoclassicism? Fundamentally, the issues examined in this document-the terminal structures in the brass sonatas-are a subset of particular surface issues that only begin to probe at the deeper understanding of Hindemith's neoclassicism. Indeed, the neoclassical ramifications of such cadential/transitional structures are perhaps more telling than the structures themselves.

In his book Neoclassicism in America, R. James Tobin makes many pertinent observations on the dissemination and proliferation of Hindemith as a neoclassicist in the mid-twentieth century, including Hindemith's move to America and his teaching post at Yale. Although the brunt of the book focuses on such figures as Walter Piston, Lukas Foss, Irving Fine, and Nikolai Lopatnikoff, there is an extensive section on European influences on American neoclassicism, in which Hindemith plays a large role.

Tobin makes note that Hindemith's "sense of musical architecture was perhaps the most highly developed of all his musical faculties."63 This statement emphasizes the importance and fundamentality of structure within the works of Hindemith; the classical formal paradigms have been preserved, but altered, and the classical tonal paradigms have been turned about completely, as shown in the previous analyses. Ian Kemp also notes that Hindemith's reverence and involvement in the realm of chamber music, as seen in his Kammermusik of the 1920s, reinforces his position as a neoclassicist, as chamber music is a distinctly classical tradition, much as the sonatas are.

63 Tobin, 22. 
To compound on this distinction, David Neumeyer further calls Hindemith an "antiromantic urban composer who thrived on clarity, concision, and linear energy."64 Evidencing this, Kemp notes that Das Marienleben, one of Hindemith's most well known works, was comprised of eighteenth-century rhythms and forms and was "deliberately unromantic in character,"65 utilizing clear linear voicing and diatonic intervals. Kemp adds that "a distaste for self-indulgent expression and an emphasis on clarity of line, texture, and form remained typical of him throughout his life."66

Not only is Hindemith's neoclassicism generated from a sparseness and directness of character, but this shows the important link between Hindemith's neoclassicism and counterpoint. The prominence of counterpoint within Hindemith's music is packaged as a new aural shift that must then be dealt with by the listener: one must learn to expect musical lines built upon horizontal motion instead of vertical motion.

Tying neoclassicism back to counterpoint, Tobin points towards eighteenthcentury composers of counterpoint (such as the sons of J.S. Bach) who invoked "the authority of the human ear." ${ }^{67}$ Hindemith likewise extolls the supremacy of listening, saying "a true musician believes only in what he hears." ${ }^{8}$ In this way, Hindemith promotes a pedagogical take on neoclassical structures: that for these structures to work, and for Hindemith's music (or anyone's music, for that matter)
${ }^{64}$ Ibid.
65 Ibid.
66 Ibid.
${ }^{67}$ Ibid, 25.
68 Ibid. 
to work, the "authority of the human ear" must ultimately reign supreme.

Hindemith's thoughts on listening and the benefit of using the natural implications ear for guidance are linked to his theories on tonal design in Series 1 and 2;

Hindemith conceived of such structures of being more natural, and disseminates such a view in Craft.

Tobin posits that the term "neo-baroque" might be better used for such composers as Stravinsky and especially Hindemith, but I believe the neoclassicism label is a fitting one. In this musical context, the term neoclassicism has to do more with the particulars of style than it does overall aesthetics, and Hindemith composes in a thoroughly neoclassical style, especially when looking at the prominent structural and stylistic cues I have highlighted thus far-most obviously, as a composer of sonatas (ostensibly the most classical form), one can conclude that Hindemith was operating well within the boundaries of neoclassicism. Indeed, the malleability of the neoclassical moniker is one that Tobin-and we- must grapple with, as there is no standardized definition of neoclassicism.

With these things in mind, we now have a working knowledge of some of the neoclassical elements of Hindemith's music. Tobin provides some insight that potentially helps give us a working, standardized definition of neoclassicism, describing it as fundamentally

a rejection of romanticism, impressionism, post-World War I expressionism, and serialism, although ... several prominent neoclassicists embraced or experimented with serial techniques in their later stages without departing entirely from the general principles of the neoclassical aesthetic. ${ }^{69}$

69 Ibid, 2. 
Fittingly, this characterization is true of Hindemith, who used quasi-serialist formulations in the first movement of the tuba sonata. Tobin goes on further to point out the separation and distinction of the composer's style from their aesthetics; ${ }^{70}$ while a composer's style may vary from piece to piece, their aesthetics fundamentally stay the same or show a much more gradual evolution. This is true of Hindemith, and is shown in the pieces studied in this document, as the earlier trombone sonata and later tuba sonata show an evolution of aesthetics, for example, the contemporaneous horn and trumpet sonata show a stylistic aberration from the same compositional year of 1939.

The disparity found in the horn sonata in the prior section, detailed above, ultimately informs our working definition of neoclassicism provided in Chapter 1. Following Tobin's definition above, the pieces I've analyzed thus far have preserved some (but not all) elements of neoclassicism. Elements of form and the notion of key areas are preserved from the classical to the neoclassical, yet Hindemith updates or otherwise re-conceives inter-key relations and formal linking structures. Tenets of harmonic structure and overall conceptions of cadential and transitional mechanisms have likewise received a neoclassical update. These elements reinforce the sense of mutability, variability, and shared underlying, large-form ideas within Hindemith's neoclassicism, ones that are most prominently displayed through cadential and transitional mutation in my analyses.

In this regard, Hindemith's neoclassicism can be understood to be a reappropriation of paradigms - the deviation from certain formal and tonal

${ }^{70}$ Ibid. 
structures that are so ingrained in the collective musical surface that said deviation becomes much more fundamental than the structures themselves. In Hindemith's neoclassicism, the tonal constructs and linking phenomena are the deviation from the collective norm, and are fundamentally indicative of this neoclassical reappropriation. Thus, one might view Hindemith's neoclassicism as a musical comment on classicism — that the fundamental structures are rooted within our Western psyche, and that the shift of a single element (here, the aspects of tonality) can create a sort of cognitive dissonance or aural tension within the listener with which they then must grapple. ${ }^{71}$

These observations call into question what it means to be a neoclassicist in the twentieth century, and firmly situate Hindemith within the neoclassical puzzle; one must sort out and ultimately reckon with these various neoclassical threads that exist as the crux of Hindemith. This includes his usage of tonality, structural forms, and the musical, pedagogical promotion of such trope-defying (or trope-embracing) ideals.

Now that we have an understanding of Hindemith's conceptions of cadence and transition, we can summarily understand the role of his Craft of Musical Composition and the inherent pedagogical ramifications of the document; these phenomena are ultimately another aspect that Hindemith wished to model in his works and the Craft, ultimately preserving the pedagogical necessity that he encapsulated within his neoclassicism. Moreover, with Hindemith, neoclassicism

${ }^{71}$ This issue is perhaps manifest in Hindemith's overall chilly reception in certain circles in the twentieth century; were audiences cognizant and keen on reconciling neoclassical structures with their prior knowledge of classicism? 
goes hand in hand with preserving and promoting this pedagogy—of music in general, and with regards to his tonal conceptions specifically. Hindemith used the sonata form trope as a conduit to present his tonal constructions and concepts to a global audience, both in and outside the conservatory setting. Hindemith's sonatas can then be thought of as a fundamentally pedagogical endeavor, similar to Schoenberg's Op. 25 dance suite, in that they inform the listener of the fundamental tonal deviation and of neoclassicism by using familiar formal structure that audiences would recognize.

It would be a rose-tinted viewpoint that all of Hindemith's music and systems of tonality make perfect aural sense; indeed, Hindemith's music is generally at odds with other twentieth century norms of chordal harmony and melodic typifiers. Continuing in the vein of pedagogy, there also exists a performance aspect as well; making each of these sonatas for the whole instrumentation of the orchestra, including various permutations of the instruments, with piano provides a platform for the budding and accomplished musician to perform and practice challenging music of the twentieth century with familiar formal aspects. It is perhaps just as well that Hindemith used these sonatas as a platform to disseminate his theories on tonality by practice instead of by rote.

In any regard, the previous analyses have shown that Hindemith retains the classical aspect in some aspects of his compositions and provides a neoclassical update to others, which relates to what Tobin describes as a dichotomy between the Dionysian and Apollonian in neoclassicism. Tobin contends that Apollonian values, classical values, are indicative of the more restrained style, clear linearity and 
symmetrical phrase structure present in such genres as Viennese classicism. Dionysius, on the other hand, is wild, erratic, and non-structured. Hindemith occupies a middle-ground niche amid this dichotomy: not completely Apollonian and not completely Dionysian. The blend of these two values is present and largely eminent in his sonatas, where broad-scale formal constructs follow the tenets of Viennese classicism, while smaller divisions of this large form are more varied, and border a sort of musical wilderness.

This blend is apparent in Hindemith's tonality as well. Hindemith's theories on tonality are fundamentally Apollonian - they come from a formal study and categorization of tonal concepts and phenomena. However, Hindemith's usage of his tonal system is varied, and as evidenced by numerous sections within the brass sonatas (for instance, the highly contentious, tritone-laden middle section between piano and tuba found in the tuba sonata ${ }^{72}$ ) can be dissonant, unpredictable and clashing, bordering that same musical wilderness. The introduction of cadential and transitional figures into this dichotomy reveals a lean towards the Apollonian, the stereotypical neoclassicality. Formal constructs in themselves smack of the measured, structured approach of the classicists; the sonata itself is a fundamentally classical trope, and so the structures within the sonatas must be likewise subordinate to the classical hierarchy, in some form or another. The cadential figures, in particular the falling tone, show a degree of form that operates within a Dionysian tonal context. Therefore, as demarcators and structural indicators that operate in this realm, interphrasal terminal descent is a fundamentally structural

${ }^{72}$ See analysis of Sonata for Tuba and Piano in chapter 3 of this document. 
phenomenon that operates within neoclassical form, and it must be characterized as a device that strengthens and preserves formal cohesion. Hindemith's adoption of these form tropes, whether he was aware of their implications or not, is indicative of a deeper connection to the form of the music and their use is an ultimately classical, form-preserving gesture.

Through this document, I have traced Hindemith's neoclassicism through the eyes of contemporaries, current scholars and through a new understanding of cadential/transitional phenomena, including a new method to categorize and quantify terminal phrase gestures that border key areas within the brass sonatas. While there are many directions this research could lead, these analyses have uncovered a mid-level formal feature of Hindemith's neoclassicism that aids our understanding and listening of his music in a more complete way. Fundamentally, Hindemith was a tonal composer, relying heavily on formal processes, and so these aspects of tonality and formality must be considered as a part of the whole of Hindemith. It is my hope that, by looking at cadential/transitional terminal gestures in Hindemith's music, these aspects can be better understood. Through this document, I hope I have inspired some to further study and reconcile the part that Hindemith's particular brand of neoclassicism —-linear, direct, and adhering to a sort of self-contained tonal logic-plays in the broader scope of twentieth-century music. 


\section{REFERENCES}

Caplin, William E. Classical Form: A Theory of Formal Functions for the Instrumental Music of Haydn, Mozart and Beethoven. Oxford University Press, 1998.

Hepokoski, James and Warren Darcy. Elements of Sonata Theory. Oxford University Press, 2006.

Hindemith, Paul. The Craft of Musical Composition, Book I: Theoretical Part. Translated by Arthur Mendel. New York: Associated Music Publishers, Inc., 1942.

- - - The Craft of Musical Composition, Book II: Exercises in Two-part Writing. Translated by Otto Ortmann. New York: Associated Music Publishers, Inc., 1941.

Kemp, Ian. Hindemith. Oxford University Press, 1970.

Neumeyer, David. The Music of Paul Hindemith. Yale University Press, 1986.

_—_. "Tonal, Formal, and Proportional Design in Hindemith's Music." Music Theory Spectrum no. 9 (1987): 93-116.

Payne, Dorothy. "The Accompanied Wind Sonatas of Hindemith: Studies in Tonal Counterpoint" PhD diss., Eastman School of Music, 1974.

"Principles and Categories." Fondation Hindemith. Accessed April 7, 2017. http://www.hindemith.info/en/life-work/biography/19331939/work/principles-and-categories. 
Samson, Jim. Music in Transition: A study of tonal expansion and atonality, 1900-1920. New York: W. W. Norton \& Company Inc., 1977.

Schubert, Giselher. "Hindemith, Paul." Grove Music Online. Oxford Music Online. Oxford University Press, accessed April 7, 2017, http://www.oxfordmusiconline.com.echo.louisville.edu/subscriber/article/g rove/music/13053.

Skelton, Geoffrey. Paul Hindemith: The Man behind the Music: A Biography. London: Victor Galancz, 1977.

Tobin, R. James. Neoclassical Music in America: Voices of Clarity and Restraint. Lanham, Maryland: Rowman \& Littlefield, 2014.

Whittall, Arnold. "Neo-classicism." Grove Music Online. Oxford Music Online. Oxford University Press, accessed April 7, 2017, http://www.oxfordmusiconline.com.echo.louisville.edu/subscriber/article/g rove/music/19723.

Further Recommended Reading and Listening

Neumeyer, David. "Counterpoint and Pitch Structure in the Early Music of Hindemith" PhD diss., Yale University, 1976.

Hindemith, Paul. Sonatas for Brass and Piano. Glenn Gould with members of the Philadelphia Brass Ensemble. Sony 52671, 1992. CD.

Scores

Hindemith, Paul. Mathis der Maler. Mainz: B. Schott’s Söhne, 1934.

—- - Sonata for Horn and Piano. Mainz: B. Schott's Söhne, 1940.

——. Sonata for Trombone and Piano. London: Schott \& Co., Ltd., 1942.

———. Sonata for Trumpet and Piano. Mainz: B. Schott's Söhne, 1940.

——- Sonata for Tuba and Piano. Mainz: B. Schott's Söhne, 1957.

——-. String Quartet no. 2, Op. 10. Mainz: B. Schott's Söhne, 1921. 


\section{APPENDIX: GLOSSARY OF TERMS}

Interphrasal terminal descent: The phenomenon by which new key areas are arrived via primarily stepwise motion, the last unit of which is primarily descending.

Motivic catalyst: The primarily stepwise unit that brings about interphrasal terminal descent. Represented by semitone cardinality notation, e.g. $(+5,-1)$ to denote an ascent by five semitones followed by a descent of one semitone.

Cadential/transitional figures: Hindemith links cadence and transition in his writings; in his music, they exhibit similar function. They herald new key areas in Hindemith's music, with cadence being more static and transition being more dynamic.

Falling tone: The (-1) segment of motivic catalysts, generally signaling motion to a structurally significant key area.

Key area: Within Hindemith's music, an area of tonality that eschews traditional key-affirming gestures and instead embraces chromaticism, yet with a sense of gravity towards a specific tonic, through repetition or stable sonorities built on that tonic. 


\section{CURRICULUM VITA}

NAME: Blake Hunter Taylor

$\begin{array}{ll}\text { ADDRESS: } & 421 \text { Franck Ave } \\ & \text { Louisville, KY } 40206\end{array}$

DOB: Danville, Kentucky - November 19, 1990

EDUCATION

\& TRAINING: $\quad$ B.M., Music Performance (Tuba)

University of Kentucky

2009-2014

M.M., Music Theory

University of Louisville

2015-2017

PROFESSIONAL

SOCIETIES: $\quad$ Pi Kappa Lambda, Lambda Chapter

Society for Music Theory

International Tuba Euphonium Association

PRESENTATIONS: Indiana University, Symposium of Research in Music Theory, February 20, 2017. "Tonal Shift, Cadence and Transition in Hindemith's Sonata for Trombone and Piano, mvt. 1."

University of Louisville, Graduate Student Research Symposium, March 25, 2017. “Analyzing Experimental Pop: A 
Cellular Approach to Non-Traditional Musical Modes of Expression." 